\title{
Mechanical Characteristics and Energy Evolution Laws for Red Bed Rock of Badong Formation under Different Stress Paths
}

\author{
Tao Wen $\mathbb{D}^{\mathrm{D}},{ }^{1,2}$ Huiming Tang $\mathbb{D}^{3,},{ }^{3,4}$ Yankun Wang, ${ }^{3}{\mathrm{Junwei} \mathrm{Ma},{ }^{4} \text { and Zhiqiang Fan }}^{3}$ \\ ${ }^{1}$ School of Geosciences, Yangtze University, Wuhan, Hubei 430100, China \\ ${ }^{2}$ The Key Laboratory of Well Stability and Fluid \& Rock Mechanics in Oil and Gas Reservoir of Shaanxi Province, \\ Xi'an Shiyou University, Xi'an 710065, China \\ ${ }^{3}$ Faculty of Engineering, China University of Geosciences, Wuhan, Hubei 430074, China \\ ${ }^{4}$ Three Gorges Research Center for Geo-Hazards of Ministry of Education, China University of Geosciences, Wuhan, \\ Hubei 430074, China
}

Correspondence should be addressed to Huiming Tang; tanghm@cug.edu.cn

Received 9 October 2018; Revised 7 March 2019; Accepted 8 April 2019; Published 2 May 2019

Academic Editor: Khalid Abdel-Rahman

Copyright (c) 2019 Tao Wen et al. This is an open access article distributed under the Creative Commons Attribution License, which permits unrestricted use, distribution, and reproduction in any medium, provided the original work is properly cited.

Exploring mechanical properties of red bed rock of Badong Formation Section two (b2) from the Three Gorges Reservoir is crucial to determine the instability mode of reservoir slopes. In order to reveal the energy evolution laws for b2 rocks under different stress paths, loading tests, unloading tests, and cyclic loading-unloading tests were conducted, respectively. The results show that stress paths have significant influences on the mechanical properties and energy evolution characteristics of b2 rocks and the failure mechanism under three stress paths is revealed. Relative to the loading tests, the mechanical parameters of b2 rocks are deteriorated under the unloading conditions. In addition, the increasing trend of cumulative dissipation energy (CDE) is similar with that of total absorption energy (TAE) and the ESE-strain curves are characterized by multistep rise. For cyclic loadingunloading tests, the areas of hysteretic loop gradually increase as the cycle times increase, and the TAEs and the coefficient of the cumulative dissipation energy (CCDE) also increase gradually with approximately linear characteristics, while the CDEs gradually increase in an abrupt rate. This work can contribute to provide the failure mechanism of b2 rocks for evaluating the stability of reservoir slopes from the energy perspective.

\section{Introduction}

With the construction and implementation of large-scale hydropower projects related to rock mass in China, a large number of engineering geological problems, such as the excavation of abutment slope, the excavation and support of underground cavern, and geological structural movement, have arisen, which seriously threaten the safety of the project and people's lives and property [1-3]. In particular, the excavation in this rock engineering is a process of unloading and stress redistribution in one or more directions of natural rock mass [4], so the mechanical characteristics of rock mass under loading and unloading conditions are essentially different, especially under soft rock conditions [5]. Moreover, the process of rock deformation and failure is always accompanied by the accumulative, dissipation, and release of the energy, which is regarded as an instability phenomenon driven by the energy [6-9]. Thus, it is necessary to understand the connections between the mechanical characteristics, the energy evolution laws, and the deformation/ failure mechanisms.

In recent years, many contributions have been made to utilize the perspective of energy to study the mechanical properties and the deformation/failure mechanism of the rock [10-13]. From initial damage to final failure, the failure of the rock undergoes three stages, including the failure of microstructures, the formation of mesoflaws and the coalescence of macrocracks $[14,15]$. As both the formation and propagation of microcracks that lead to the failure of the rock consume much energy, the rock 
behaviors, such as damage and yield, represent a process of energy dissipation. However, the failure of the rock was related to the release of strain energy [16], the rock failure is essentially a series of complex processes of energy conversion $[17,18]$. The internal loss of rock materials could produce energy dissipation in the form of heat energy, and the external friction between test equipment and rock specimens could also lead to energy dissipation in the form of friction energy [19]. Besides that, the confining pressure could significantly influence the failure modes and the energy conversion laws of the rock [20]. The mechanical properties, energy dissipation laws, and damage characteristics for different rock types under complex stress conditions are slightly different under different confining pressures $[5,18,21,22]$. Hence, the energy conversion laws and the establishment of appropriate specific energy parameters that relate to the energy play a prominent part in the analysis of the damage of the rock and its evolution characteristics $[23,24]$.

Otherwise, the red bed rocks of the Badong Formation of the Triassic are mainly distributed in Western Hubei and Eastern Chongqing, which are typical slippery beds in the Three Gorges Reservoir area, especially b2 rocks [25]. The b2 rocks are mainly composed of carbonate and argillaceous minerals. Under the long-term geostress and groundwater immersion conditions, the b2 rocks would gradually disintegrate and mud along the interface between the soft and hard materials, which results in the deterioration of their properties and formation of layered soft surfaces [26]. Once the unfavorable boundary conditions are formed, the deformation and failure of b2 rocks along the weak surfaces may be directly induced by the gravity and external factors $[27,28]$. Therefore, in-depth understanding of the physical and mechanical properties of $\mathrm{b} 2$ rocks is of great significance for the analysis of the slope stability.

Although attempts have been made to study the physical and mechanical characteristics of the rock under loading and unloading conditions based on continuous stress equations, such as failure phenomena, constitutive models, and strength criteria [29-33], the research on the deformation/failure mechanism determined by the energy theory is insufficient thoroughly and not systematic. Especially, quantitative study on the energy evolution laws of b2 rocks in the Three Gorges Reservoir area under complex stress paths is less involved, and the study on the deformation/failure mechanism of b2 rocks from the perspective of the energy evolution is neglected. To better understand the complicated deformation and failure process and to reveal the energy evolution laws of the red bed rock, the rock tests for the red bed rock were conducted under different stress paths. Based on the energy method, the mechanical characteristics and the energy evolution laws of the red bed rock were analyzed under different stress paths and the microstructural analysis with the SEM technology was also conducted. The research results can provide a theoretical foundation for early identification, prediction, and prevention of bedding rock landslide in reservoir area.

\section{Methods for Determining the Energy Parameters}

2.1. Loading or Unloading Condition. Based on the stressstrain curve of the rock under the loading or unloading condition, the energy distribution laws at a given stress state can be obtained as shown in Figure 1. The area of ABCDEN surrounded by the loading or unloading curve and the strain axis can be defined as the total absorption energy (TAE) that represents the total work done by the external forces to the rock. The area of ABCDO can be defined as the elastic strain energy (ESE) before peak strength (PS). The area of DENM can be defined as the cumulative dissipation energy (CDE) after the PS, and the area of PQM can be defined as the residual elastic strain energy after the PS. In addition, the deformation and failure process of the rock can be divided into five stages, that is, the compaction stage, the elastic stage, the yield stage, the postpeak failure stage, and the residual stage, as shown in Figure 1.

According to the energy conservation theorem, the following formula can be obtained [34]:

$$
U_{0}=U_{\mathrm{d}}+U_{\mathrm{e}},
$$

where $U_{0}$ is the TAE, $U_{\mathrm{d}}$ is the CDE, and $U_{\mathrm{e}}$ is the ESE that can be released. The unit of $U_{0}, U_{\mathrm{d}}$, and $U_{\mathrm{e}}$ is " $\mathrm{Pa}$," which is the same as the unit of stress.

On the basis of the first law of thermodynamics, energy dissipation is unidirectional and irreversible, but energy release is bidirectional and reversible under certain conditions. Under the state of the conventional triaxial loading, the energy parameters of each part of the rock mass unit in the main stress unit can be expressed as

$$
\begin{aligned}
& U_{0}=\int \sigma_{1} d \varepsilon_{1}+2 \int \sigma_{3} d \varepsilon_{3}, \\
& U_{\mathrm{e}}=\frac{1}{2 E_{0}}\left[\sigma_{1}^{2}+2 \sigma_{3}^{2}-2 \mu\left(2 \sigma_{1} \sigma_{3}+\sigma_{3}^{2}\right)\right],
\end{aligned}
$$

where is $E_{0}$ and $\mu$ are the elastic modulus that corresponds to $50 \%$ of the PS and Poisson's ratio, respectively.

Besides, the CDE before the PS denoted by $U_{\mathrm{d}}^{\text {pre }}$ is equal to the minus of the TAE before the PS to the ESE before the PS, expressed as follows:

$$
\begin{aligned}
U_{\mathrm{d}}^{\mathrm{pre}}=U_{0}^{\mathrm{p}}-U_{\mathrm{e}}^{\mathrm{p}}= & \int_{0}^{\varepsilon_{1 \mathrm{p}}} \sigma_{1} d \varepsilon_{1}+2 \int_{0}^{\varepsilon_{3 \mathrm{p}}} \sigma_{3} d \varepsilon_{3}-\frac{1}{2 E_{0}} \\
& \cdot\left[\sigma_{1 \mathrm{p}}^{2}+2 \sigma_{3 \mathrm{p}}^{2}-2 \mu\left(\sigma_{3 \mathrm{p}}^{2}+2 \sigma_{1 \mathrm{p}} \sigma_{3 \mathrm{p}}\right)\right]
\end{aligned}
$$

where $U_{0}^{\mathrm{p}}$ is the TAE when the stress reaches the PS and $U_{\mathrm{e}}^{\mathrm{p}}$ is the ESE when the stress reaches the PS.

In the postpeak failure stage, the failure of the rock specimen requires additional energy, which is partly due to the work done by the external forces that converts into the dissipation energy and partly due to the release of the elastic strain energy before the PS. That will further lead to the propagation of the microcracks. The releasable elastic strain energy (expressed as $U_{\text {rel }}$ ) can be determined by using the following formula: 


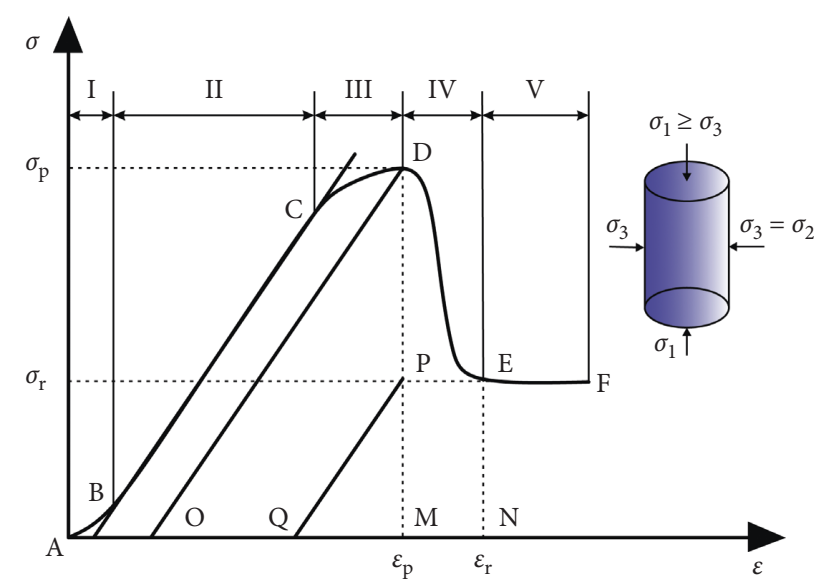

FIgURE 1: Energy distribution laws in the deformation and failure process of the rock.

$$
U_{\text {rel }}=U_{\mathrm{e}}^{\mathrm{p}}-U_{\mathrm{e}}^{\mathrm{r}},
$$

where $U_{\mathrm{e}}^{\mathrm{r}}$ is the residual elastic strain energy after the failure of the rock specimen, which can be calculated based on equation (3) that only replaces $\sigma_{1}$ and $\sigma_{3}$ by the residual axial stress $\left(\sigma_{1 \mathrm{r}}\right)$ and the residual confining pressure $\left(\sigma_{3 \mathrm{r}}\right)$, respectively.

Moreover, the energy in the postpeak failure stage will be consumed due to the perforation failure of the original microcracks or the formation of new microcracks; thus, the $\mathrm{CDE}$ at the postpeak stage can be recomposed as follows:

$$
U_{\mathrm{d}}^{\mathrm{post}}=\int_{\varepsilon_{1 \mathrm{p}}}^{\varepsilon_{1 \mathrm{r}}} \sigma_{1} d \varepsilon_{1}+2 \int_{\varepsilon_{3 \mathrm{p}}}^{\varepsilon_{3 \mathrm{r}}} \sigma_{3} d \varepsilon_{3}
$$

2.2. Cyclic Loading-Unloading Condition. The typical hysteresis loop curve of the cyclic loading-unloading test for rocks is shown in Figure 2. The TAE that defines the work done by external force to the rock specimen is equivalent to the area enclosed by the loading curve and the abscissa axis. The ESE is equivalent to the area enclosed by the unloading curve and the abscissa axis, while the area of the hysteresis loop formed by the loading curve, and the unloading curve is regarded as the CDE that equals the difference between the TAE and the ESE.

Based on the typical hysteresis loop curve of the cyclic loading-unloading test, the dissipation energy (DE) in the $i$ th hysteresis loop can be expressed as follows, respectively:

$$
\begin{aligned}
& S_{\mathrm{d} i}=S_{\mathrm{l} i}-S_{\mathrm{u} i}, \\
& S_{\mathrm{l} i}=\sum_{\text {load }} \frac{\left(\sigma_{k}+\sigma_{k+1}\right)\left(\varepsilon_{k+1}-\varepsilon_{k}\right)}{2}, \\
& S_{\mathrm{u} i}=\sum_{\text {unload }} \frac{\left(\sigma_{\mathrm{u} k}+\sigma_{\mathrm{u}(k+1)}\right)\left(\varepsilon_{\mathrm{u}(k+1)}-\varepsilon_{\mathrm{u} k}\right)}{2},
\end{aligned}
$$

where $S_{\mathrm{d} i}$ represents the area of the hysteresis loop is the DE formed by the $i$ th hysteresis loop; $S_{1 i}$ is the area enclosed by the $i$ th loading curve and the abscissa axis; $S_{\mathrm{u} i}$ is the area

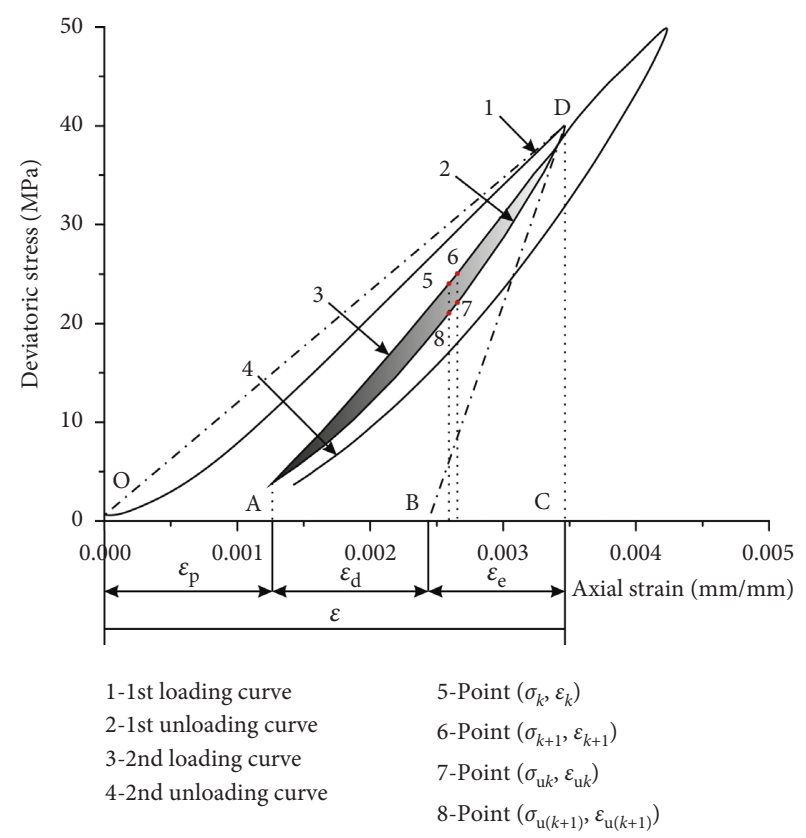

Figure 2: Typical hysteresis loop curve of the cyclic loadingunloading test for the rock specimen.

enclosed by the $i$ th unloading curve and the abscissa axis; $\sigma_{k}$ and $\varepsilon_{k}$ or $\sigma_{k+1}$ and $\varepsilon_{k+1}$ are the stress and the strain of the $k$ point or the $k+1$ point in the $(i+1)$ th loading curve, respectively; and $\sigma_{\mathrm{u} k}$ and $\varepsilon_{\mathrm{u} k}$ or $\sigma_{\mathrm{u}(k+1)}$ and $\varepsilon_{\mathrm{u}(k+1)}$ are the stress and the strain of the $k$ point or the $k+1$ point in the $(i+1)$ th unloading curve, respectively.

In the cyclic loading-unloading test, the hysteresis loop curve enclosed by the $i$ th unloading curve and the $i$ th loading curve are open interval, while the hysteresis loop curve enclosed by the $i$ th unloading curve and the $(i+1)$ th loading curve is closed interval. From the energy perspective, a part of the TAE will be stored within the rock in the form of the ESE when the elastic deformation will be produced in the process of loading. However, the rest of the TAE will be converted into the DE, which will result in plastic deformation inside the rock. Therefore, the release of the ESE in a cycle has little effect on the deformation and failure of the rock in the subsequent cycle. Nevertheless, the DE can aggravate the damage of the rock, and the internal structure of the rock is further damaged. Thus, the CDE that represents as the sum of the DE in each cycle can preferably measure the amount of the energy dissipation of the rock under different cycles, which can be expressed as

$$
U_{\mathrm{d}}(i)=\sum_{j=1}^{i} S_{\mathrm{d} j},
$$

where $U_{\mathrm{d}}(i)$ is the CDE in the $i$ th cycle and $j$ is the $j$ th cycle with a range of 0 and $i$.

The TAE $\left(U_{0}(i)\right)$ in the $i$ th cycle is the sum of the area enclosed by the abscissa axis and part of the $j$ th $(j \leq i)$ loading curve that can be determined by using the axial strain. The axial strain in the $j$ th loading curve is larger than the 
maximum axial strain in the $(j-1)$ th loading curve. Thus, the TAE can be expressed as

$$
U_{0}(i)=\sum_{j=1}^{i} S_{1 j} .
$$

The ESE that can be released in the $i$ th cycle is equivalent to the difference between the TAE and the CDE, which can be expressed as according to equation (1):

$$
U_{\mathrm{e}}(i)=U_{0}(i)-U_{\mathrm{d}}(i)
$$

In the cyclic loading-unloading test, the ratio of the $\mathrm{CDE}$ to the TAE is defined as the coefficient of the cumulative dissipation energy (CCDE), which can be expressed as

$$
P(i)=\frac{U_{\mathrm{d}}(i)}{U_{0}(n)},
$$

where $P(i)$ is the CCDE in ith cycle, $U_{0}(n)$ is the TAE after all cycles finish, and $n$ is the total cycle times.

In equation (11), a rock ceases to bear a load at $P=1$, as the rock is completely destroyed; a value of $P=0$ suggests that no damage within the rock occurred, and the work performed by external forces is absolutely transferred into the ESE. Therefore, the CCDE can be used to measure the degree of the failure of the rock.

\section{Test Materials and Procedures}

3.1. Test Materials. The sampling site is located in Dongrangkou Town, Badong Country, Hubei Province, China, near the Yangtze River and approximately $70 \mathrm{~km}$ into the upper reach of the Three Gorges Dam. The purple-red siltstones in the Middle Triassic Badong Formation Section two (b2) from the Three Gorges Reservoir area are prepared according to the relevant standards, which has a height of approximately $100 \mathrm{~mm}$ and a diameter of approximately $50 \mathrm{~mm}$. The $\mathrm{b} 2$ rocks are characterized by their monomineralic nature with quartz, chlorite, illite, montmorillonite, and calcite. During the preparation of rock specimens, geometric configurations should be ensured to avoid any irregularities that may affect the test results. Cylindrical specimens are recovered from the siltstone blocks by coring perpendicularly to the bedding plane. The end of the specimens is grinded using a face grinder to ensure that the two planar ends are parallel to each other and perpendicular to the longer dimension. Sonic wave tests are carried out before the triaxial tests to eliminate the abnormal rock specimens.

Triaxial loading tests, triaxial unloading tests and triaxial cyclic loading-unloading tests under different confining pressures were conducted with a servo-controlled testing machine by the Institute of Rock and Soil Mechanics of Chinese Academy of Sciences, as shown in Figure 3. The maximum axial load capacity of the machine is $4600 \mathrm{kN}$. The axial strain measurement and the lateral strain measurement of rock specimens are conducted with miniature linear variable differential transformers (LVDTs) with a relative error of $0.6 \%$ in $1 \mathrm{~mm}$ for the axial strain measurement and $1.3 \%$ in $3 \mathrm{~mm}$ for the lateral strain measurement.
3.2. Loading Test Procedures. To determine the mechanical properties and the energy evolution laws of b2 rocks under loading conditions, the confining pressure in the loading tests is set to be four levels, that is, $2,4,8$, and $16 \mathrm{MPa}$, respectively. The loading tests employ the way that keeps the confining pressure unchanged but increases the axial stress. The axial loading control way is also utilized to ensure the constant gradient loading. For the loading test, the stress determined based on the hydrostatic stress is applied with a loading rate of $0.25 \mathrm{kN} / \mathrm{s}$ after the pressure chamber is closed. Then keeping the confining pressure stable, the axial stress is applied with a loading rate of $0.25 \mathrm{kN} / \mathrm{s}$ until the rock specimen is broken.

3.3. Unloading Test Procedures. To reveal the mechanical properties and the energy evolution laws of b2 rocks under the unloading conditions, the initial confining pressure in the unloading tests is set to be four levels, that is, also 2, 4, 8 , and $16 \mathrm{MPa}$, respectively. The unloading tests employ the way that keeps the axial stress unchanged but decreases the confining pressure. The axial loading control way is also utilized to ensure the constant gradient loading before the rock specimen is destroyed; nevertheless, the loading control way is converted into the circumferential deformation control when the axial stress reaches $80 \%$ of the PS that corresponds to the loading test at the same confining pressure. For the unloading test, the stress determined based on the hydrostatic stress is applied with a loading rate of $0.25 \mathrm{kN} / \mathrm{s}$ after the pressure chamber is closed. Then, keeping the axial stress stable when the axial stress is up to $80 \%-95 \%$ of the PS that corresponds to the loading conditions, the confining pressure is applied with an unloading rate of $0.25 \mathrm{kN} / \mathrm{s}$ until the rock specimen is broken.

To minimize the influences of different stress paths on the mechanical characteristics of rocks, the deformation parameters $(E$ and $\mu$ ) should be calculated based on the following formulas $[9,35]$ :

$$
\left.\begin{array}{l}
E=\frac{\left(\sigma_{1}-2 \mu \sigma_{3}\right)}{\varepsilon_{1}}, \\
\mu=\frac{\left(B \sigma_{1}-\sigma_{3}\right)}{\left[\sigma_{3}(2 B-1)-\sigma_{1}\right]}, \\
B=\frac{\varepsilon_{3}}{\varepsilon_{1}}
\end{array}\right\}
$$

It is common knowledge that the relationship between $\sigma_{1}$ and $\sigma_{3}$ are linear in the Mohr-Coulomb criterion and the linear relation $\sigma_{1}=k \sigma_{3}+b$ can be calculated by regression analysis. Thus, the shear strength parameters $(c$ and $\varphi)$ can be obtained by the following formulas $[36,37]$ :

$$
\begin{aligned}
& \varphi=\arcsin \left(\frac{k-1}{k+1}\right), \\
& c=\frac{b(1-\sin \varphi)}{2 \cos \varphi} .
\end{aligned}
$$




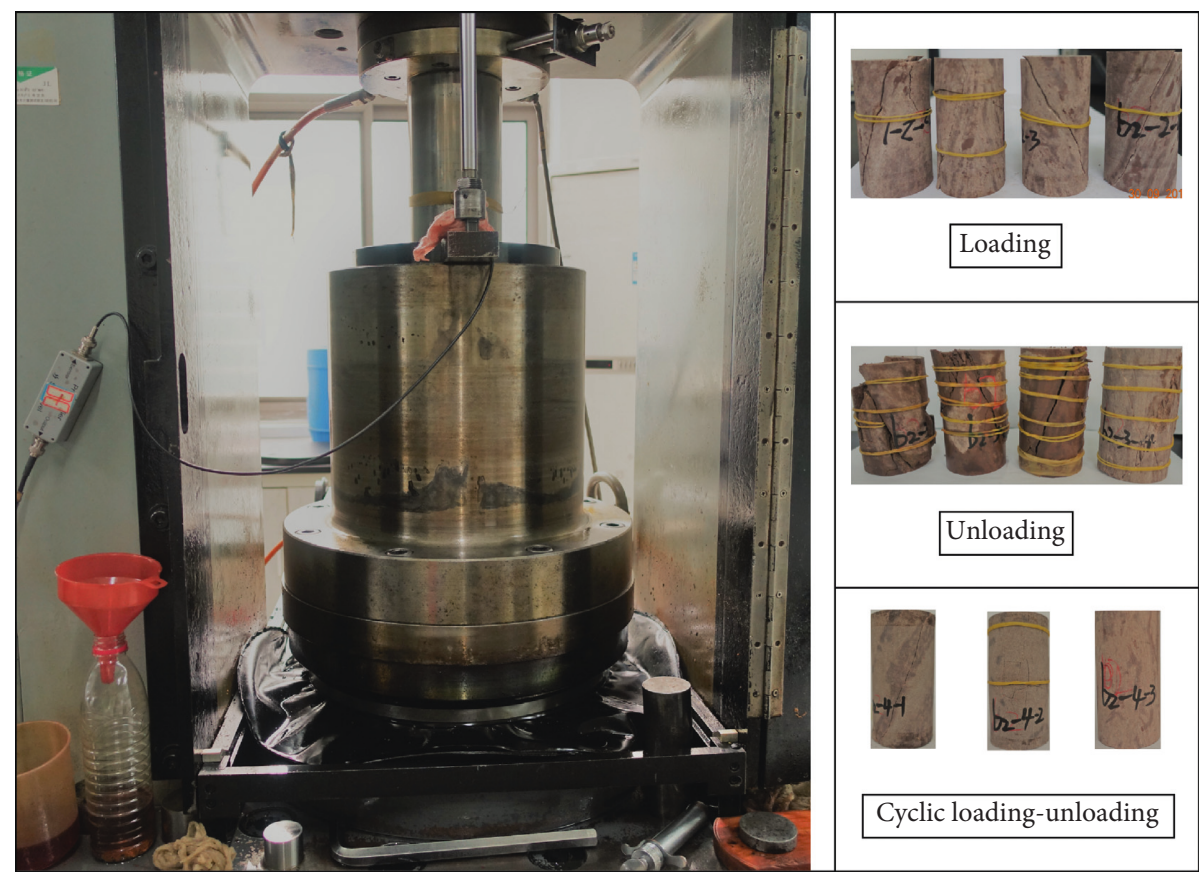

FIgURE 3: The test instrument.

3.4. Cyclic Loading-Unloading Test Procedures. To study the mechanical properties and the energy evolution laws of b2 rocks under cyclic loading-unloading conditions, the tests with the confining pressures of $4 \mathrm{MPa}, 8 \mathrm{MPa}$, and $16 \mathrm{MPa}$, respectively, were conducted. Taking the test with the confining pressure of $4 \mathrm{MPa}$ as an example, the axial loading control is utilized with a loading rate of $0.25 \mathrm{kN} / \mathrm{s}$ in the initial loading stage, and the axial loading control is also utilized with an unloading rate of $0.25 \mathrm{kN} / \mathrm{s}$ in the initial unloading stage. When the axial stress reaches an approximately predetermined load, the unloading process of the axial stress starts. Then the axial stress in the unloading process decreases to $4 \mathrm{MPa}$, and the next loading process of the axial stress is carried out again. The difference between two adjacent maximum loads before the rock is destroyed is $10 \mathrm{MPa}$, which ensures that more than 5 cycles can be achieved. The above steps are carried out repeatedly until the rock is destroyed. When the axial stress reaches approximately the maximum load, the lateral deformation control is utilized with a deformation rate of $0.001 \mathrm{~mm} / \mathrm{s}$ until the rock is destroyed. The purpose of this approach is to prevent a sudden failure of the rock near the PS and to obtain the complete stress-strain curve. The loading way of cyclic loading-unloading test is shown in Figure 4 .

\section{Mechanical Characteristics under Different Stress Paths}

4.1. Loading Test Results. The measured stress-strain curves under loading conditions are shown in Figure 5. It can be seen that, with the increase of the confining pressure, the ductility characteristics of $\mathrm{b} 2$ rocks are more obvious. The axial strain increases rapidly and presents linear characteristic before the

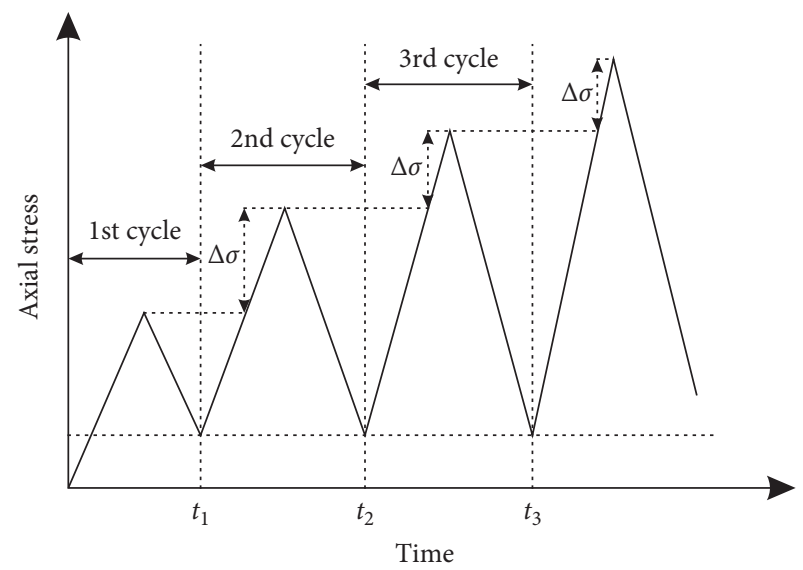

FIgURE 4: Loading way of the cyclic loading-unloading test.

PS, while the lateral strain increases slowly. Moreover, the curves slightly bend downwards near the PS, which reveals that the damage of $\mathrm{b} 2$ rocks aggravates and the strength of b2 rocks decrease so that b2 rocks are inevitably destroyed. It is worth noting that the PS under the confining pressure of $16 \mathrm{MPa}$ is two times than that under the confining pressure of $8 \mathrm{MPa}$. After the PS, b2 rock under different confining pressures destroys and the axial stress drops rapidly with a multilevel failure characteristic, which indicates that b2 rock presents a ductility property. However, a certain residual strength (RS) exists permanently, and the higher the confining pressure is, the greater the RS is.

Table 1 shows the mechanical parameters of $\mathrm{b} 2$ rocks under loading conditions. The change laws of the deformation parameters are not obvious with the increasing confining pressure. However, the PS and the RS increase with increasing confining pressure. The shear strength 


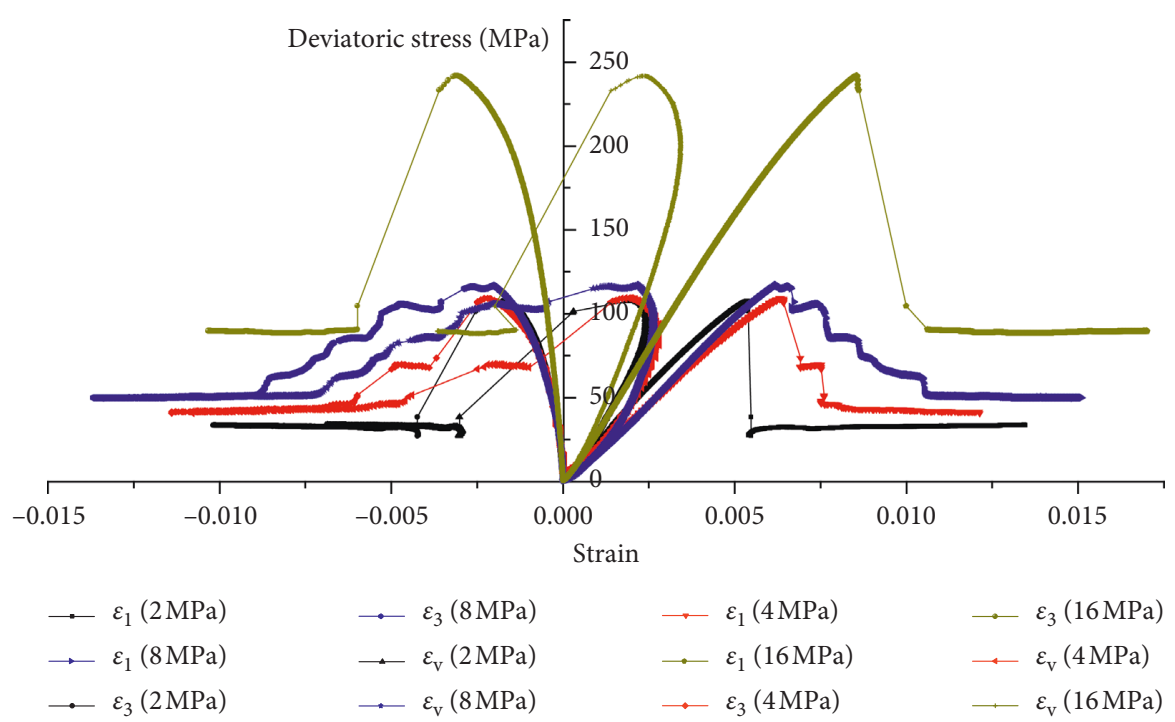

Figure 5: The curves of b2 rocks for triaxial loading tests.

TABLE 1: The mechanical parameters of b2 rocks under loading conditions.

\begin{tabular}{|c|c|c|c|c|c|c|c|c|c|c|}
\hline \multirow{2}{*}{ Specimen no. } & \multirow{2}{*}{$\sigma_{3}(\mathrm{MPa})$} & \multirow{2}{*}{$E_{0}(\mathrm{GPa})$} & \multirow{2}{*}{$\mu$} & \multicolumn{3}{|c|}{ PS parameters } & \multicolumn{3}{|c|}{ RS parameters } & \multirow{2}{*}{$\beta\left(\left(^{\circ}\right)\right.$} \\
\hline & & & & $\sigma_{\mathrm{p}}(\mathrm{MPa})$ & $c(\mathrm{MPa})$ & $\varphi\left({ }^{\circ}\right)$ & $\sigma_{\mathrm{r}}(\mathrm{MPa})$ & $c(\mathrm{MPa})$ & $\varphi\left(^{\circ}\right)$ & \\
\hline b2-2-1 & 2 & 21.13 & 0.244 & 107.562 & \multirow{4}{*}{9.959} & \multirow{4}{*}{56.631} & 33.581 & \multirow{4}{*}{5.995} & \multirow{4}{*}{36.707} & $77^{\circ} 14^{\prime}$ \\
\hline b2-2-2 & 4 & 16.88 & 0.236 & 109.312 & & & 41.566 & & & $72^{\circ} 14^{\prime}$ \\
\hline b2-2-3 & 8 & 17.63 & 0.237 & 125.031 & & & 49.939 & & & $65^{\circ} 22^{\prime}$ \\
\hline b2-2-4 & 16 & 31.20 & 0.207 & 257.858 & & & 89.641 & & & $73^{\circ} 18^{\prime}$ \\
\hline
\end{tabular}

$\sigma_{\mathrm{p}}$ is PS; $\sigma_{\mathrm{r}}$ is RS; $\beta$ is the angle of rupture.

parameters at the RS are less than those at the PS. $c$ and $\varphi$ at the RS are $60.2 \%$ and $64.8 \%$ of these at the PS, respectively, which illustrates that although the rocks are destroyed, they still have a certain bearing capacity. The angle of rupture that defines the angle between the fracture surface and the horizontal direction decreases with the increase of the confining pressure under low confining pressure conditions and then increases when the confining pressure is $16 \mathrm{MPa}$.

4.2. Unloading Test Results. The measured stress-strain curves under unloading conditions are shown in Figure 6. It also can be seen that with the increased confining pressure, the ductility characteristics of b2 rocks are more obvious. The axial strain increases rapidly and presents linear characteristic before the PS, while the lateral strain increases slowly. The yield platform at the PS under unloading conditions is smaller than that under loading conditions, and the failure of b2 rock is more sudden and severe without a multilevel failure characteristic. Comparing the loading and unloading curves of b2 rocks, the PS under unloading conditions is less than that under loading conditions, and the axial strain that reaches the PS under unloading conditions is also less than that under loading conditions, indicating that it is beneficial to the failure of the rock under unloading condition. Furthermore, with the increase of the confining pressure, no obvious plastic characteristics appear under unloading conditions. It can be concluded that the loading at the axial direction is the main cause of the rock failure under loading conditions while the expansion at the lateral direction is the major factor of the rock failure under unloading conditions.

The mechanical parameters of $\mathrm{b} 2$ rocks under unloading conditions are shown in Table 2. The residual deviatoric stress increases while the angle of rupture decreases with the increase of the confining pressure. The confining pressure after the failure of the rock is very small or even close to 0 at the initial confining pressures of $2 \mathrm{MPa}, 4 \mathrm{MPa}$, and $8 \mathrm{MPa}$, which indicates that the unloading rate has a little influence on the variation of the confining pressure. However, the confining pressure after the failure of the rock is approximately $5 \mathrm{MPa}$ at the initial confining pressures of $16 \mathrm{MPa}$, which illustrates that the residual bearing capacity is still high at high confining pressure.

According to equation (13), the cohesion and the internal friction angle at the PS of b2 rocks under unloading conditions are $9.637 \mathrm{MPa}$ and $52.62^{\circ}$, respectively, which are $96.8 \%$ and $92.9 \%$ of that under loading conditions, indicating that the deterioration of the mechanical parameters of $\mathrm{b} 2$ rocks under unloading conditions is more serious than that under loading conditions and the rock failure under unloading condition is more likely to occur than that under the loading condition. This is because the rock has different failure mechanisms under different stress paths. The main failure mode of the rock under loading conditions is shear failure while the rock gradually transforms the shear failure 


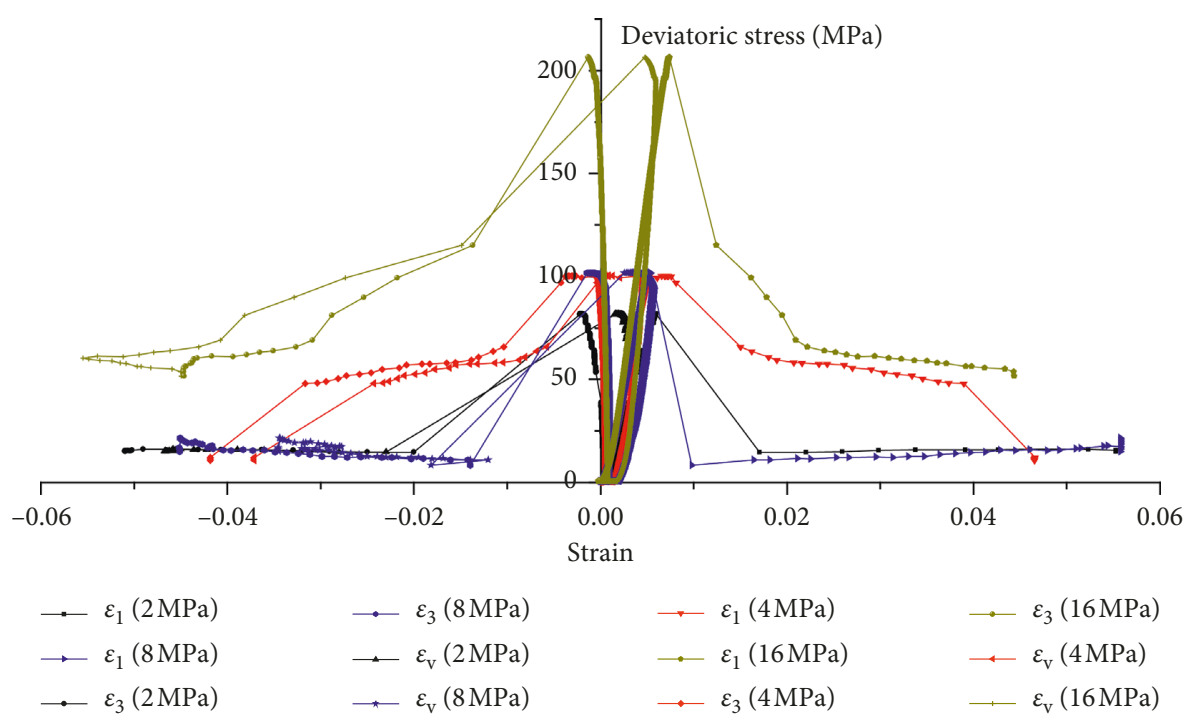

Figure 6: The curves of b2 rocks for triaxial unloading tests.

TABLE 2: The mechanical parameters of b2 rocks under unloading conditions.

\begin{tabular}{lccccc}
\hline Specimen no. & $\sigma_{3}(\mathrm{MPa})$ & $\left(\sigma_{10} / \sigma_{\mathrm{c}}\right)(\%)$ & $\sigma_{\mathrm{p}}(\mathrm{MPa})$ & $\sigma_{30}(\mathrm{MPa})$ & $\sigma_{\mathrm{r}}(\mathrm{MPa})$ \\
\hline b2-3-1 & 2 & 90 & 81.6 & 0.122 & 15.142 \\
b2-3-2 & 4 & 95 & 100.432 & 0.500 & $7\left(^{\circ}\right)$ \\
b2-3-3 & 8 & 80 & 101.662 & 0.252 & 71.261 \\
b2-3-4 & 16 & 95 & 206.419 & 5.013 & 21.223 \\
\hline
\end{tabular}

$\sigma_{10}$ is the axial stress when the unloading process starts; $\sigma_{\mathrm{c}}$ is the PS that corresponds to the loading test at the same confining pressure; $\sigma_{30}$ is the confining pressure when the rock specimen is destroyed.

mode into the failure mode of tension and shear coexistence under unloading conditions. Therefore, the unloading of the confining pressure will reduce the transverse restraint of the rock, and in that condition, more energy will be provided for the rock failure, which leads to the propagation of the tension-shear cracks.

4.3. Cyclic Loading-Unloading Test Results. As shown in Figure 7 the complete stress-strain curves for b2 rocks are obtained under the confining pressures of $4 \mathrm{MPa}, 8 \mathrm{MPa}$, and $16 \mathrm{MPa}$, respectively. The rock specimens corresponding to the three groups of confining pressures are b2$4-1, \mathrm{~b} 2-4-2$, and b2-4-3 for b2 rocks, respectively. It should be noted that for b2-4-1 and b2-4-2 rocks, due to the small initial unloading stress by artificially setting a smaller initial value and the lack of the cycle times, the value of the peak point of the last cycle in the stress-strain curve is greatly different from the PS. But that does not affect the research on the mechanical properties of b2 rocks in this paper. Figure 7 presents that as the cycle times increase, the minimum strain that corresponds to the hysteretic loop and the area of the hysteretic loop gradually increases. In addition, the slope of the reloading curve increases with increasing of the cycle times, and the residual deformation also increases. Based on the geometric shape of the test curves, the reloading curves and the unloading curves are also concave in geometry, indicating that the microcracks extended to both ends are repressed again during the unloading process. When the stress exceeds the limit strength in the last loading, the microcracks inside the rocks expand gradually. The effective elastic modulus of the rock specimen first increases and then decreases, which results in a concave feature of the reloading curve.

The first cyclic loading-unloading curve includes the initial loading curve and the first unloading curve, which have a characteristic of an upward parabolic for both the first loading curve and the first unloading curve. Similarly, the second cyclic loading-unloading curve includes the second loading curve and the second unloading curve. Although second unloading curve also has a characteristic of an upward parabolic, the second loading curve presents upward parabolic characteristic in lower stress and downward parabolic characteristic in higher stress. The shape characteristics of the $i$ th $(i>2)$ cycle are basically consistent with the second cycle. When the rock specimen is destroyed, there has obvious brittleness characteristic in the postpeak failure stage, which can be utilized to determine the RS distinctly. It is noted that every cyclic loading-unloading curve is not closed and the stress that corresponds to the reloading curve is higher than that the unloading curve at the same axial strain. Moreover, there exists residual deformation inside the rock specimen, which indicates that the rock specimen not only produces elastic deformation that can be restored but also produces plastic deformation that cannot be recovered in the unloading process. 


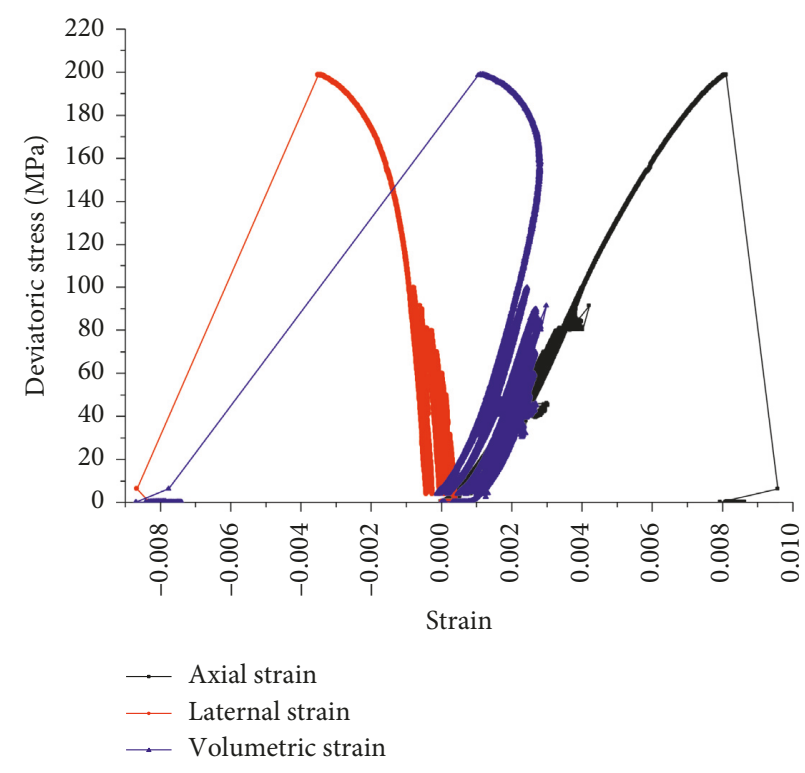

(a)

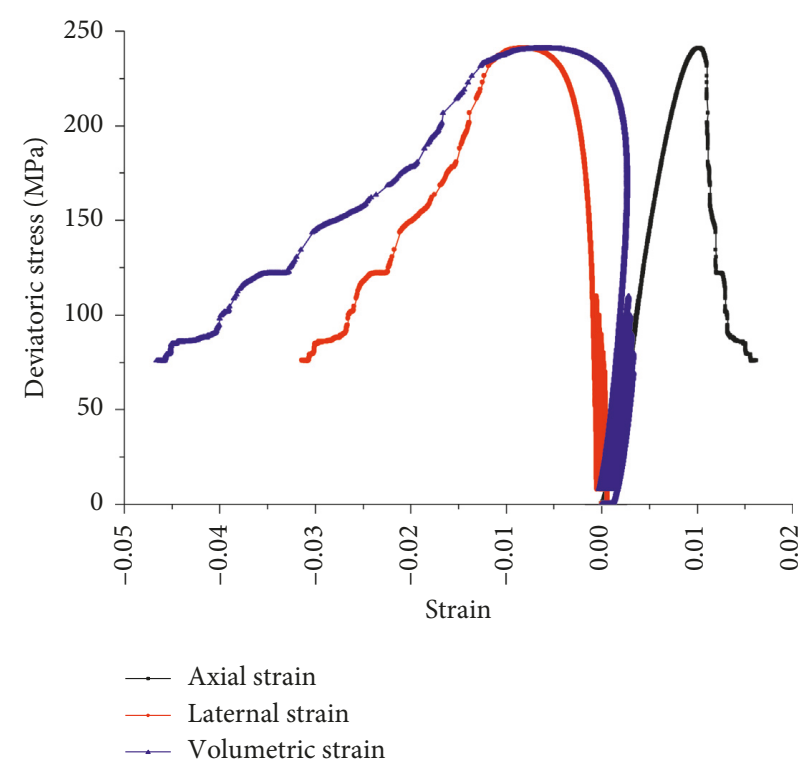

(b)

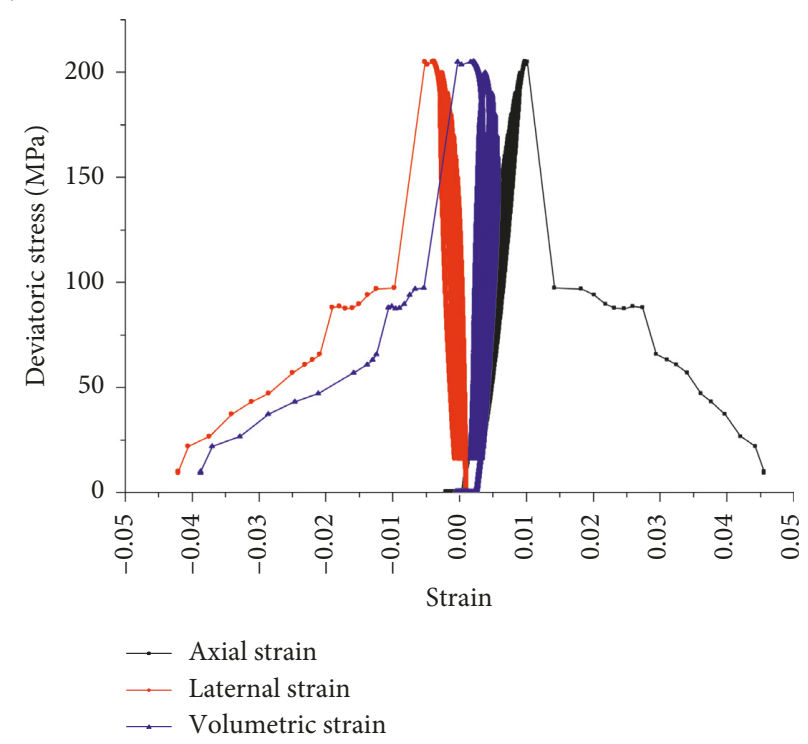

(c)

Figure 7: The stress-strain curves of b2 rocks under cyclic loading-unloading conditions: (a) b2-4-1; (b) b2-4-2; (c) b2-4-3.

The results in Table 3 presenting the basic parameters of b2 rocks show that, as the confining pressure increases, the PS increases gradually, except for b2-4-3 rock. For the same rock type, the PS in the triaxial loading test is more than that in the cyclic loading-unloading test at the same confining pressure. One of the reasons is that the damage of the rock in the cyclic loading-unloading test will be more severe than that in the triaxial loading test. The other of the reasons is that some microcracks are pressed in the process of loading while these microcracks are loose in the process of unloading. This will lead to the decline of the strength of the rock. As the cycle times increase, the initial microcracks will expand gradually and new microcracks will generate. Due to the inhomogeneity of particle size and structure within the rock, local tensile stress is generated within the rock, and the microcracks first occur between particles with weaker cohesion under the local tensile stress. Moreover, all rocks have a great rupture angle and the variation trend of the rupture angle is consistent with that of the axial strain at the peak point. It is obvious that the rocks have a characteristic of discreteness due to the difference of the density and the wave velocity. However, the low dispersion of the rocks still satisfies the research on the analysis of the mechanical properties of b2 rocks in the cyclic loading-unloading tests in this paper.

\section{Energy Evolution Laws under Different Stress Paths}

5.1. Loading Test Results. The energy parameters at the PS in the stress-strain curves can be calculated based on equations (1)-(3), and the relationships between the TAE, ESE, CDE, 
TABLE 3: Test results of rock specimens under cyclic loading-unloading conditions.

\begin{tabular}{lccccccccc}
\hline Specimen no. & $H(\mathrm{~mm})$ & $D(\mathrm{~mm})$ & $\rho(\mathrm{g} / \mathrm{cm})$ & $\mathrm{WV}(\mathrm{km} / \mathrm{s})$ & $\sigma_{3}(\mathrm{MPa})$ & $\mathrm{CT}$ & $\sigma_{\mathrm{p}}(\mathrm{MPa})$ & $\varepsilon_{1 \mathrm{p}}$ & $\beta$ \\
\hline b2-4-1 & 96.88 & 49.53 & 2.68 & 5.27 & 4 & 7 & 203.0954 & 0.008077 & $76^{\circ} 40^{\prime}$ \\
b2-4-2 & 97.21 & 49.46 & 2.67 & 5.49 & 8 & 6 & 249.0354 & 0.010038 & $81^{\circ} 10^{\prime}$ \\
b2-4-3 & 97.24 & 49.41 & 2.61 & 4.96 & 16 & 7 & 221.2942 & 0.009788 & $78^{\circ} 50^{\prime}$ \\
\hline
\end{tabular}

$H$ is the height of the rock specimen; $D$ is the diameter; $\rho$ is the density; $\mathrm{WV}$ is the wave velocity; $\varepsilon_{1 \mathrm{p}}$ is the axial strain at the peak point; CT is the cycle time.

and confining pressure for $\mathrm{b} 2$ rocks are obtained as shown in Table 4. According to Table 4, the TAE and the CDE increase with increasing confining pressure and there are good linear relationships among them. In addition, the ratio of the CDE to the TAE at the PS increases with the increase of the confining pressure and then decreases when the confining pressure is $16 \mathrm{MPa}$, which indicates that the rock under high confining pressure stores more energy than that under low confining pressure.

To further analyze the energy evolution laws at different confining pressures, the stress-strain and strain energy parameters curves of b2 rocks are plotted and shown in Figure 8. The ESE of b2 rock takes up a large proportion of the TAE before the yield stage. After the yield stage, the increase rate of the ESE slows down while the value of the ESE is still increasing. The reason is that before the stress reaches the PS, the plastic deformation produces and the microcracks generate, propagate, and coalescence, which consumes some energy. The ESE reaches the maximum at the PS, and then most of the ESE releases instantaneously and transforms into the CDE which can be conducive to the propagation and coalescence of the microcracks until the rock is destroyed. After the PS, the ESE can be maintained at a certain value. In contrary, the $\mathrm{CDE}$ is slightly lower than the ESE before the yield stage while the CDE increases rapidly after the yield stage, which can be regarded as the symbol of the failure of the rock. In the postpeak failure stage, the increase trend of the CDE is consistent with that of the TAE. Compared with the uniaxial test, the failure of the rock under triaxial test consumes more energy because the confining pressure has restrained the formation and development of the microcracks and more external work that makes the rock destroyed needs to do by the test machine.

5.2. Unloading Test Results. To obtain the energy parameters of b2 rocks under unloading conditions, the deformation parameters under different confining pressures should be determined by using equation (12), as shown in Table 5 . The elastic modulus has an incremental linear relationship with the increase of the confining pressure. Table 6 presents the energy parameters under different confining pressures, which are calculated by using equations (1)-(6). According to Table 6 , at the same confining pressure, the TAE, ESE, and CDE at PS or at RS are larger than those under loading conditions, which suggests that the failure of the rock under unloading conditions consumes more energy. Moreover, the TAE, ESE, and CDE under unloading conditions also increase with the increase of the confining pressure. The CDE at the PS just takes up a small part of the
TABLE 4: The analysis of energy parameters when the stress reaches the PS.

\begin{tabular}{lccccc}
\hline $\begin{array}{l}\text { Specimen } \\
\text { no. }\end{array}$ & $\begin{array}{c}\sigma_{3} \\
(\mathrm{MPa})\end{array}$ & $\begin{array}{c}U_{0} \\
(\mathrm{MPa})\end{array}$ & $\begin{array}{c}U_{\mathrm{d}} \\
(\mathrm{MPa})\end{array}$ & $\begin{array}{c}U_{\mathrm{e}} \\
(\mathrm{MPa})\end{array}$ & $U_{\mathrm{d}} / U_{0}$ \\
\hline $\mathrm{b} 2-2-1$ & 2 & 0.3108 & 0.2585 & 0.0523 & 0.8317 \\
$\mathrm{~b} 2-2-2$ & 4 & 0.3637 & 0.3082 & 0.0555 & 0.8474 \\
$\mathrm{~b} 2-2-3$ & 8 & 0.3622 & 0.3152 & 0.0471 & 0.8702 \\
$\mathrm{~b} 2-2-4$ & 16 & 1.1158 & 0.9059 & 0.2100 & 0.8119 \\
\hline
\end{tabular}

total CDE while the releasable ESE employs a significant part of the ESE at the PS. Meanwhile, the more the energy consumed, the higher the strength of the rock, and the greater the deformation of the rock.

Figure 9 plots and shows the stress-strain and strain energy parameters curves of b2 rocks. Before the stress reaches the PS, the ESE approximately accounts for $90 \%$ of the TAE. Although the ESE gradually increases, the increase rate of the ESE gradually decreases. That is because the plastic deformation is produced and some energy is consumed due to the generation, propagation, and coalescence of the microcracks. The ESE reaches the maximum at the PS and then most of the ESE are released and transformed into the CDE that is used for the growth of microcracks for the rock and just a small amount of the ESE is stored inside the rock specimen. Compared with the loading test results, the evolution laws of the energy parameters are basically identical, while the CDE before the PS is very little under unloading conditions. When the rock is destroyed, the CDE increases dramatically and the ratio of the CDE to the TAE is greater than that under loading conditions.

It can be concluded from Figure 9 that the energy evolution laws of b2 rocks under loading and unloading conditions are generally similar. The TAE of the rock under unloading conditions increases faster with the increase of the axial strain and reaches a greater final value than that under loading conditions. Compared with loading conditions, in the prepeak stage the ESE of the rock under unloading conditions increases with increasing axial strain at a higher rate, while the $\mathrm{CDE}$ has a relatively lower increase rate. However, in the postpeak failure stage, the release rate of the ESE under loading conditions exceeds that under unloading conditions, while the CDE has a relatively lower increase rate. The rock fails with a relatively small postpeak axial strain mainly because of the confining pressure that restricts the development of the microcracks.

5.3. Cyclic Loading-Unloading Test Results. Based on the above equations that can be calculated, the energy 


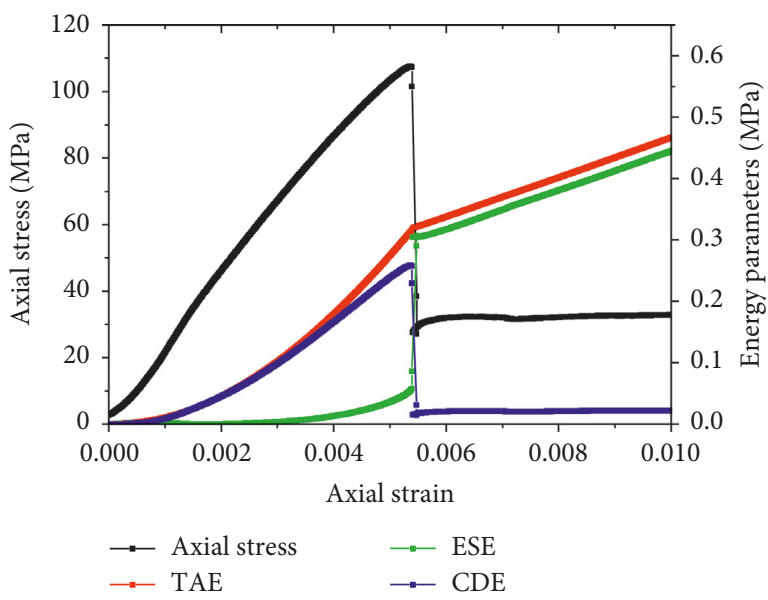

(a)

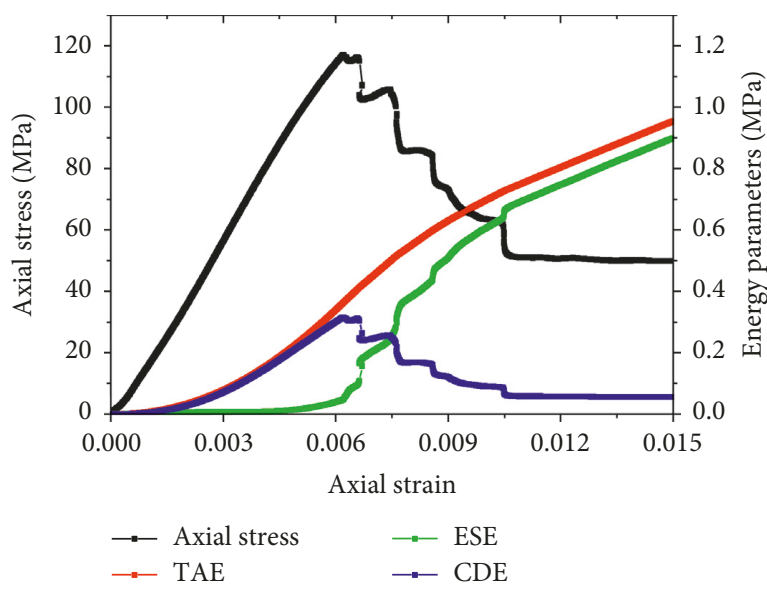

(c)

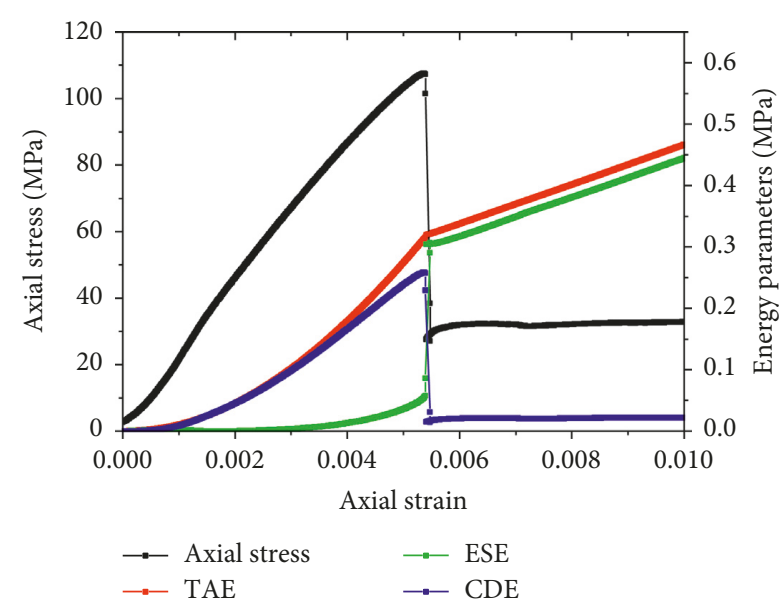

(b)

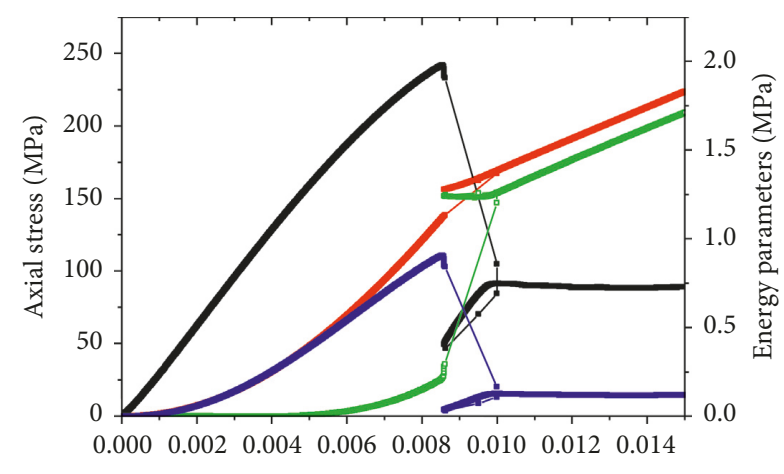

Axial strain

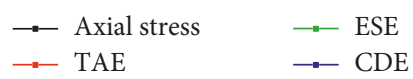

(d)

Figure 8: The energy evolution laws of b2 rocks under loading conditions: (a) $2 \mathrm{MPa}$; (b) $4 \mathrm{MPa}$; (c) $8 \mathrm{MPa}$; (d) $16 \mathrm{MPa}$.

TABLE 5: The deformation parameters under different confining pressures.

\begin{tabular}{lccccc}
\hline$\sigma_{3}(\mathrm{MPa})$ & 0 & 2 & 4 & 8 & 16 \\
\hline$E_{0}(\mathrm{MPa})$ & 7.041 & 13.687 & 18.955 & 22.618 & 29.478 \\
$\mu$ & 0.095 & 0.150 & 0.069 & 0.120 & 0.036 \\
\hline
\end{tabular}

TABLE 6: The energy parameters under different confining pressures.

\begin{tabular}{lcccccccc}
\hline Specimen no. & $\sigma_{3}(\mathrm{MPa})$ & $U_{0}^{\mathrm{p}}(\mathrm{kPa})$ & $U_{0}^{\mathrm{r}}(\mathrm{kPa})$ & $U_{\mathrm{d}}^{\mathrm{pre}}(\mathrm{kPa})$ & $U_{\mathrm{e}}^{\mathrm{p}}(\mathrm{kPa})$ & $U_{\mathrm{d}}^{\mathrm{post}}(\mathrm{kPa})$ & $U_{\mathrm{e}}^{\mathrm{r}}(\mathrm{kPa})$ & $U_{\text {rel }}(\mathrm{kPa})$ \\
\hline b2-1-1 & 0 & 212.43 & 217.02 & 0 & 212.43 & 146.18 & 70.84 & 141.59 \\
b2-3-1 & 2 & 246.28 & 314.16 & 2.52 & 243.75 & 305.95 & 8.2 \\
b2-3-2 & 4 & 272.39 & 405.73 & 4.66 & 267.72 & 389.96 & 15.77 \\
b2-3-3 & 8 & 296.4 & 348.28 & 67.01 & 229.38 & 346.73 & 1.55 & 225.55 \\
b2-3-4 & 16 & 817.65 & 1426.83 & 61.99 & 755.66 & 1181.17 & 245.66 & 510 \\
\hline
\end{tabular}

$U_{0}^{\mathrm{r}}$ is the TAE when the stress reaches the RS.

parameters, values of the CDE, TAE, and CCDE are shown in Table 7. Meanwhile, Figure 10 presents the curves of energy parameters-cycle times under cyclic loadingunloading conditions. The comprehensive analysis of Figure 10 shows the evolution laws of the TAE, CDE, ESE, and CCDE with the variation of the cycle times, which are expressed as follows:
(1) In Figure 10(a), the TAEs of b2 rocks are relatively small at the initial loading-unloading stage, while as the cycle times increase, the TAEs increase gradually. For b2 rocks, the increase trends of the TAEs in the first 5 cycles are consistent for different confining pressures. However, in the last cycle, the TAEs of b24-1 and b2-4-2 rocks suddenly increase in an abrupt 


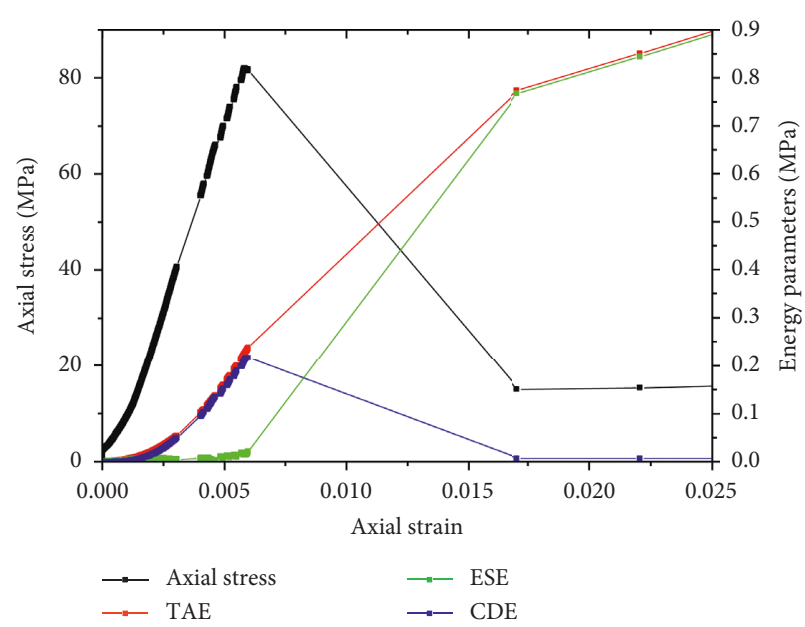

(a)

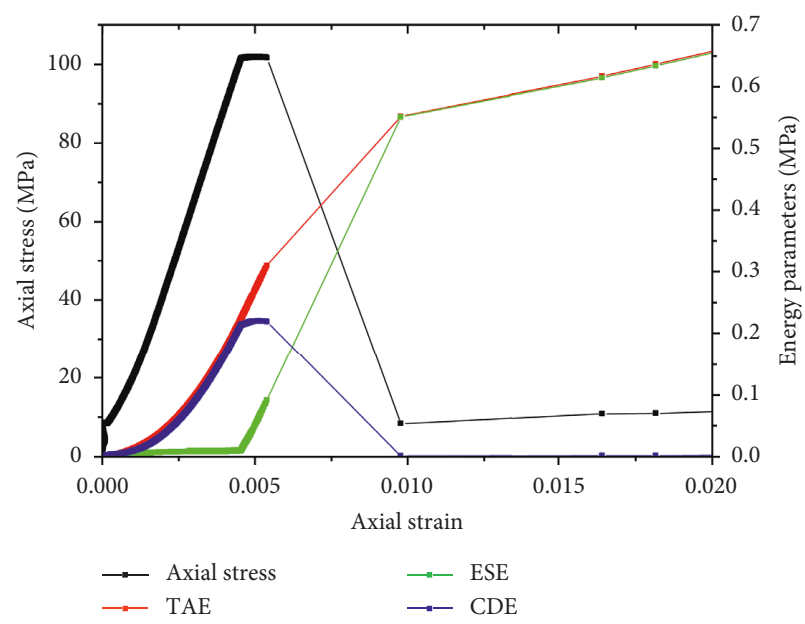

(c)

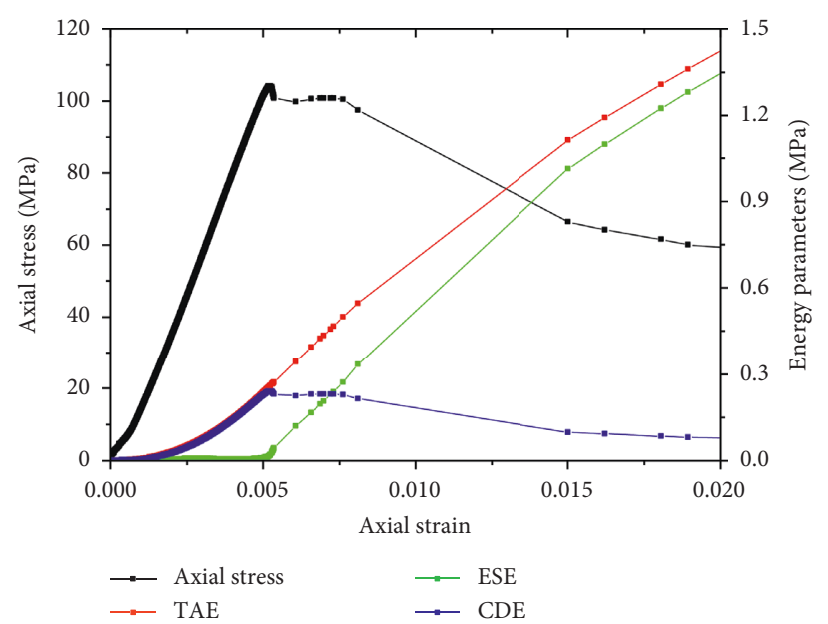

(b)

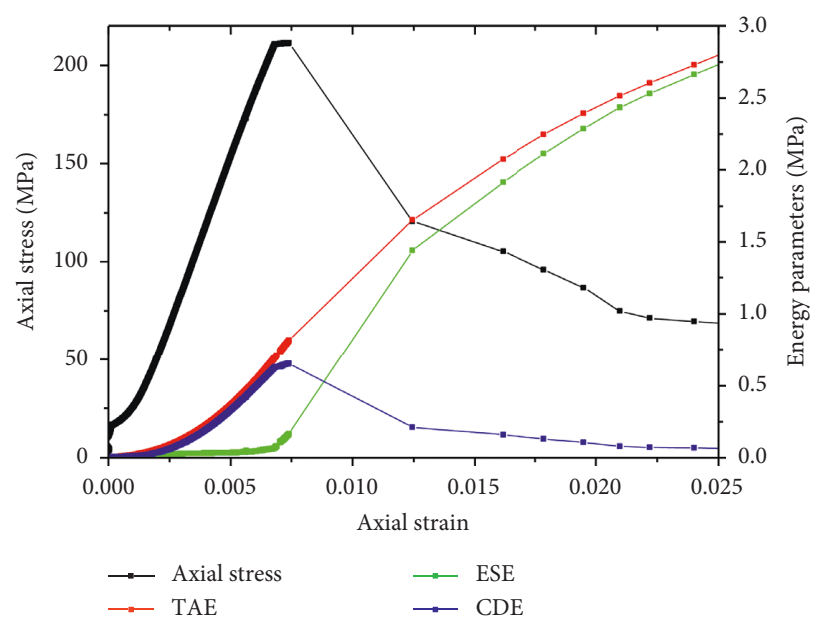

(d)

Figure 9: The energy evolution laws of b2 rocks under unloading conditions: (a) $2 \mathrm{MPa}$; (b) $4 \mathrm{MPa}$; (c) $8 \mathrm{MPa}$; (d) $16 \mathrm{MPa}$.

rate, and they are even higher than that of b2-4-3 rock. This is due to the high PS of b2-4-1 and b2-4-2 rocks and the shortage of the cycle times. Thus, the increase trends of the TAEs of b2-4-1 and b2-4-2 rocks do not commendably reflect the relationships between the TAE and the cycle times.

(2) In Figure 10(b), as the cycle times increase, the CDEs of b2 rocks increase gradually. However, the CDEs of b2 rocks are relatively small at the initial loadingunloading stage because the axial stress is relatively low at this stage, which accompanied by the closure of the micropores or microcracks inside the rock. When the cycle times increases, the CDEs also increase in an abrupt rate. The reason is that the expansion of the microcracks or the formation of new microcracks or the formation of the plastic zone at the tip of the microcracks also needs to consume much energy. For b2 rocks, the increase trends of the CDEs in the first 5 cycles are consistent for different confining pressures. However, in the last cycle, the CDEs of b2-4-1 and b24-2 rocks suddenly increase in an abrupt rate, which is caused by the lack of the cycle times.
(3) In Figure 10(c), as the cycle times increase, the ESEs of b2 rocks increase gradually in the first few cycle times, while the ESEs reduce gradually in the last cycle time. This is because most of the ESEs stored in the rock are transformed into the CDE when the failure of the rock occurs. However, the ESEs of b2-41 and b2-4-2 rocks still increase, contrary to b2-4-3 rock. It should be noted that the cycle times of b2-4-1 and b2-4-2 rocks shown in the figure are small relative to the cycle times required for the destruction of the rock. Thus, in this case, the ESEs can increase with the increase of the cycle times.

(4) In Figure 10(d), as the cycle times increase, the CCDEs of $b 2$ rocks increase gradually. The CCDEs of b2-4-1 and b2-4-2 rocks at the initial stage are small due to the characteristics of high PS and low cycle times of the rocks. However, the curves of the CCDE and the cycle times for the other rocks are basically linear, and the differences of CCDE under different cycle times are relatively small with an approximate value of 0.1 while the range of the CCDE is $0-0.75$ under different confining pressures. 
TABLE 7: Energy parameters of rocks under cyclic loading-unloading conditions.

\begin{tabular}{lcccccccc}
\hline \multirow{2}{*}{ Specimen no. } & \multirow{2}{*}{ Energy parameters } & \multicolumn{3}{c}{ Cycle times } \\
& & 1 & 2 & 3 & 4 & 5 & 6 \\
\hline \multirow{3}{*}{ b2-4-1 } & TAE & 0.0551 & 0.0741 & 0.0954 & 0.1193 & 0.1613 & 0.1896 & 0.8410 \\
& CDE & 0.0021 & 0.0054 & 0.0150 & 0.0227 & 0.0230 & 0.0312 & 0.6312 \\
& CCDE & 0.0389 & 0.0731 & 0.1571 & 0.1901 & 0.1425 & 0.1646 & 0.7505 \\
\hline \multirow{3}{*}{ b2-4-2 } & TAE & 0.1032 & 0.1297 & 0.1580 & 0.1888 & 0.2222 & 1.4366 & - \\
& CDE & 0.0034 & 0.0082 & 0.0137 & 0.0226 & 0.0351 & 1.0351 & - \\
& CCDE & 0.0334 & 0.0631 & 0.0867 & 0.1198 & 0.1578 & 0.7205 & - \\
\hline \multirow{3}{*}{ b2-4-3 } & TAE & 0.5372 & 0.6017 & 0.6724 & 0.7516 & 0.8444 & 0.9605 & 1.0422 \\
& CDE & 0.0447 & 0.0940 & 0.1545 & 0.2313 & 0.3338 & 0.4803 & 1.0303 \\
& CCDE & 0.0832 & 0.1561 & 0.2298 & 0.3078 & 0.3953 & 0.5000 & 0.9886 \\
\hline
\end{tabular}

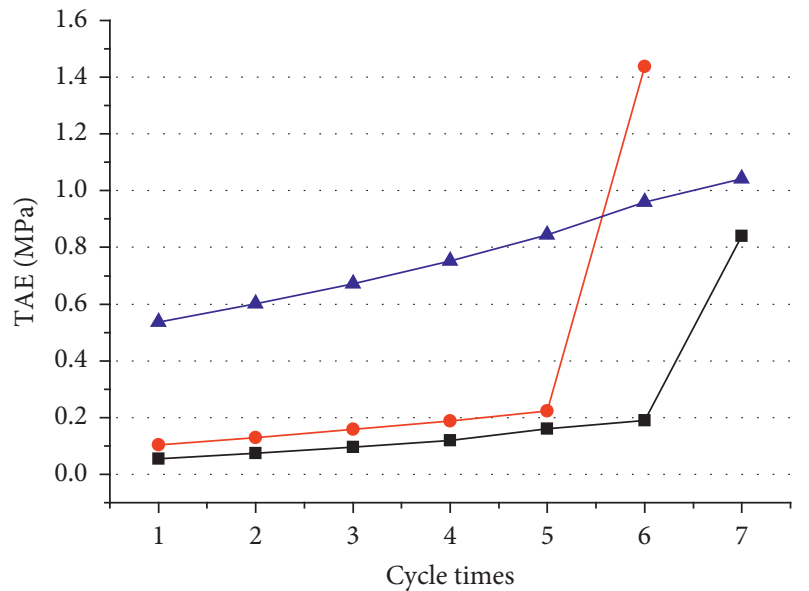

$\rightarrow-b 2-4-1$

$\rightarrow$ b2-4-2

$\sim \mathrm{b} 2-4-3$

(a)

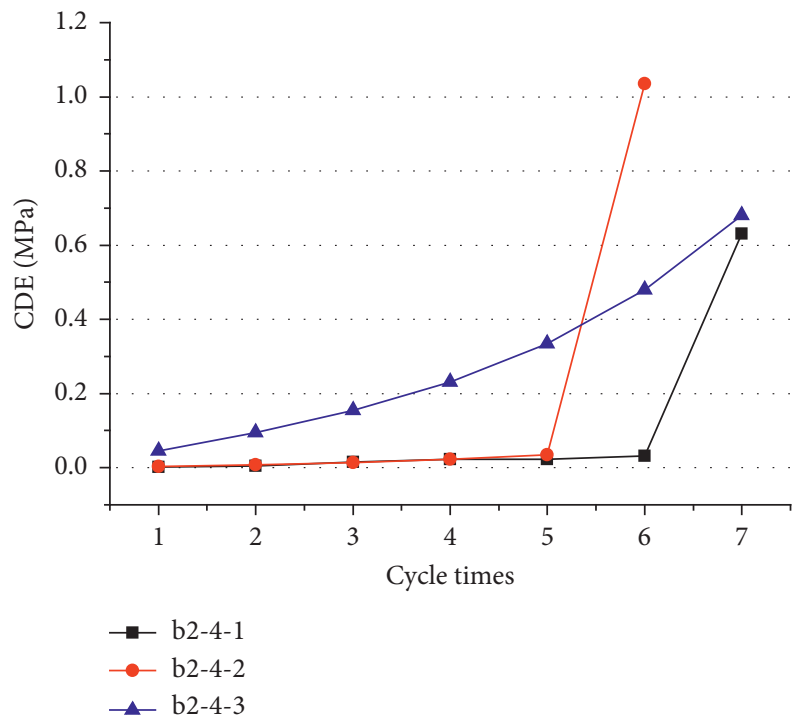

(c)

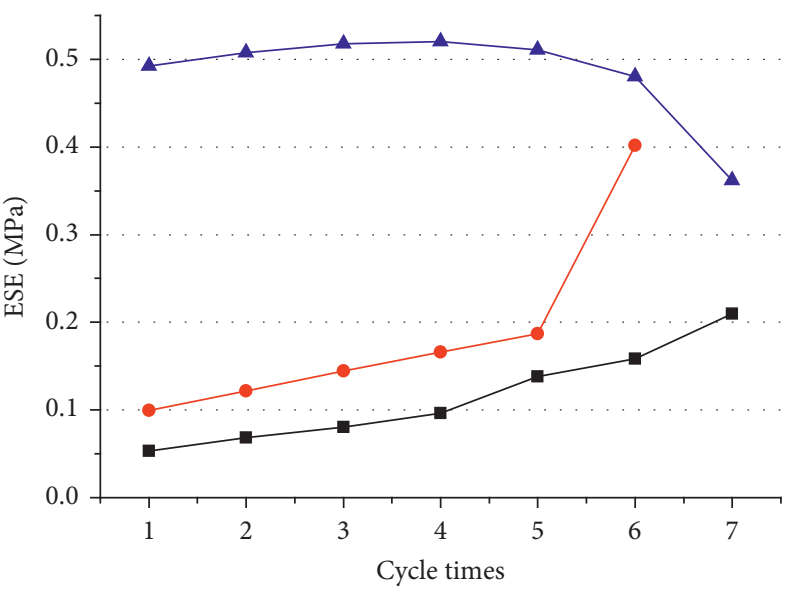

$\rightarrow \mathrm{b} 2-4-1$

$\rightarrow$ b2-4-2

$\rightarrow$ b2-4-3

(b)

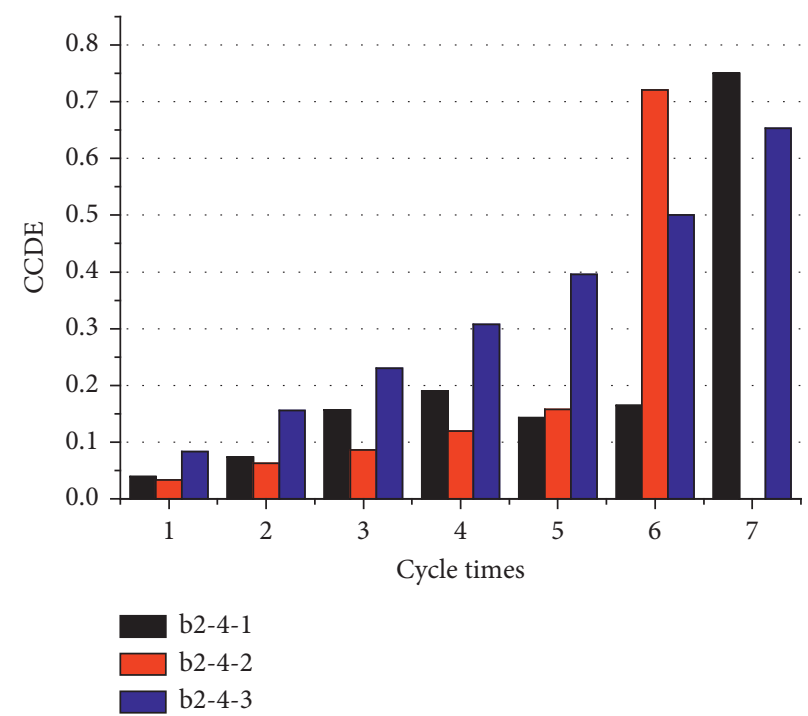

(d)

FIgURE 10: Relation curves of energy parameters and cycle times under cyclic loading-unloading: (a) TAE; (b) ESE; (c) CDE; (d) CCDE.

Figure 11 shows the relationship between the CCDE and the axial strain. As the axial strain increases, the CCDEs increase gradually under different confining pressures. Only the CCDEs of b2-4-1 rock in the third and fourth cycles are higher than that in the fifth and sixth cycles because of the external disturbance during the unloading process. 


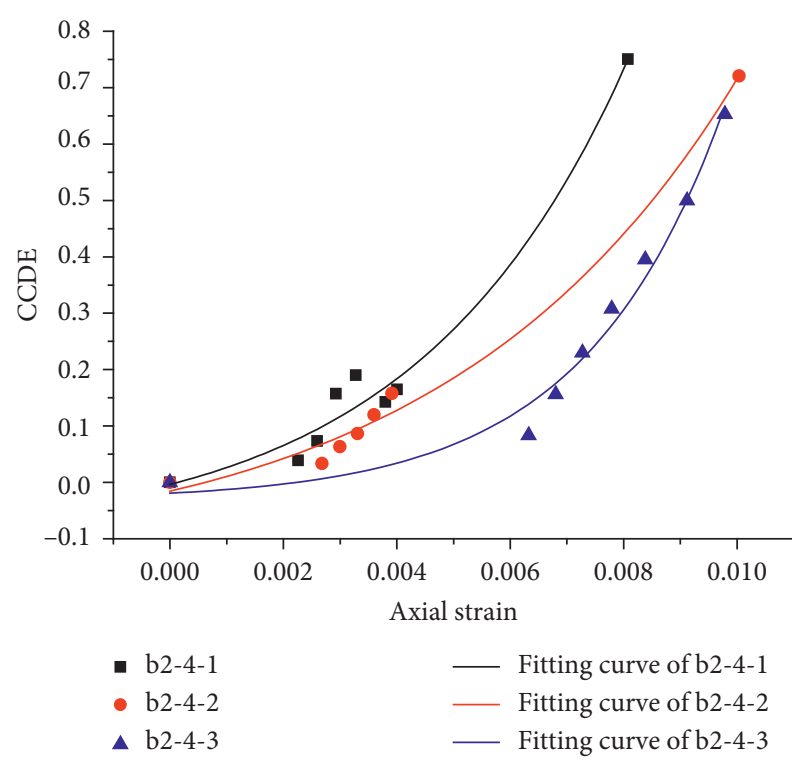

FIgURE 11: Relation curves of the CCDE and the axial strain for b2 rock specimens.

According to the fitted results, the relationship between the CCDE and the axial strain conforms to several functions, such as the polynomial function, the logarithmic function, and the exponential function. While the best fitted function is the exponential function based on the optimization fitting. Therefore, in this paper the exponential function $\left(P=A_{1} \exp \left(A_{2} * \varepsilon_{1}\right)+A_{3}\right)$ is selected to fit the relationship between them, and the result is shown in Table 8 . The results show that the CCDE represents the increasing rate of the dissipation energy in the process of the deformation and failure of the rock.

\section{Discussion}

To reveal the failure features of b2 rocks under different confining pressures, the SEM tests were conducted and the microstructural analysis of failure surface of the rock was carried out. Figure 12(a) shows the typical failure modes and the SEM images of $\mathrm{b} 2$ rocks under the loading conditions. It can be seen form Figure 12(a) that the failure modes of the rock specimens present shear fracture with a single surface and the rock specimens are destroyed along weak shear surface. The shear surface is accompanied by many rock powders that are generated by the friction between the blocks. Due to the existence of hidden bedding surfaces, the macroscopic fracture surfaces of the rock specimens do not necessarily destroy along the fracture angle that is calculated from the internal friction angle but very likely along the potential bedding surfaces. Figure 12(a) also presents that the microstructure features of b2-2-3 rock which are observed through the SEM analyses. Under the confining pressure of $8 \mathrm{MPa}$, fresh purple-red fracture surface and several slip steps are obviously observed when the fracture surface is enlarged 280 times. When the fracture surface is enlarged 5000 times, some elliptical rock powders without orientated array exist in the partially uneven position and the
TABle 8: The fitted formulas of cumulative energy dissipation coefficient and axial strain.

\begin{tabular}{lcc}
\hline Specimen no. & Fitted equations & $R^{2}$ \\
\hline $\mathrm{b} 2-4-1$ & $P=0.0971 \exp \left(\varepsilon_{1} / 0.0037\right)-0.1008$ & 0.9705 \\
$\mathrm{~b} 2-4-2$ & $P=0.1219 \exp \left(\varepsilon_{1} / 0.0051\right)-0.1373$ & 0.9874 \\
$\mathrm{~b} 2-4-3$ & $P=0.013 \exp \left(\varepsilon_{1} / 0.0025\right)-0.0321$ & 0.9747 \\
\hline
\end{tabular}

$R^{2}$ is the correlation coefficient between the CCDE and the axial strain.

particles have significant inhomogeneity. In addition, it can be seen that the shear scratches showed by the red circle in Figure 12(a) can be vaguely seen while the slip direction is not distinct in the fracture surface, which indicates that the forces acting on the fracture surfaces are relatively dispersed and the contact forces between adjacent blocks are relatively small when the blocks move.

Figure 12(b) shows the typical failure modes and the SEM images of b2 rocks under the unloading conditions. It can be seen form Figure 12(b) that b2 rocks are more fractured than that under the loading conditions at the same confining pressure and the number of fractured blocks increases obviously. Moreover, there are shear fracture for b23-1 rock and b2-3-3 rock, Y-shaped shear failure for b2-3-2 rock, and X-shaped shear failure for b2-3-4 rock; dense splitting fractures inside the rock specimens under different confining pressures, indicating that the rock specimens have obvious transverse dilatancy signs and conjugate shear fracture surface occurs under high confining pressure. However, the rock specimens present basically shear failure with a single surface under the loading conditions. Figure 12(b) also presents that the microstructure features of b2-3-7 rock are observed through the SEM analyses. Under the confining pressure of $8 \mathrm{MPa}$, fresh blue-gray fracture surface and several slip steps are obviously observed when the fracture surface is enlarged 600 times. It can also be seen that some elliptical rock powders exist in the partially uneven position and the particles have significant inhomogeneity. When the fracture surface is enlarged 1200 times, the shear scratches showed by the red circle and the slip direction showed by the red arrow in Figure 12(b) can be obviously seen in the fracture surface, which indicates that the forces acting on the fracture surfaces are relatively concentrated and the contact forces between adjacent blocks are large when the blocks move.

Figure 12(c) shows the typical failure modes and the SEM images of b2 rocks under the cyclic loading-unloading conditions. It can be seen form Figure 12(c) that the failure modes of the rock specimens are not unique under different confining pressures, which include splitting failure, tensile failure, Y-shaped shear failure for b2-4-2 rock, and X-shaped shear failure for b2-4-3 rock. By comparing the rock specimens before and after testing, the cracks for b2 rocks gradually transform from single shear cracks to X-shaped shear cracks as the confining pressure increases. Figure 12(c) also presents that the microstructure features of b2-4-1 rock are observed through the SEM analyses. Under the confining pressure of $4 \mathrm{MPa}$, fresh purple-red fracture surface and several slip steps are obviously observed when the fracture surface is enlarged 500 times. It can be seen that many 


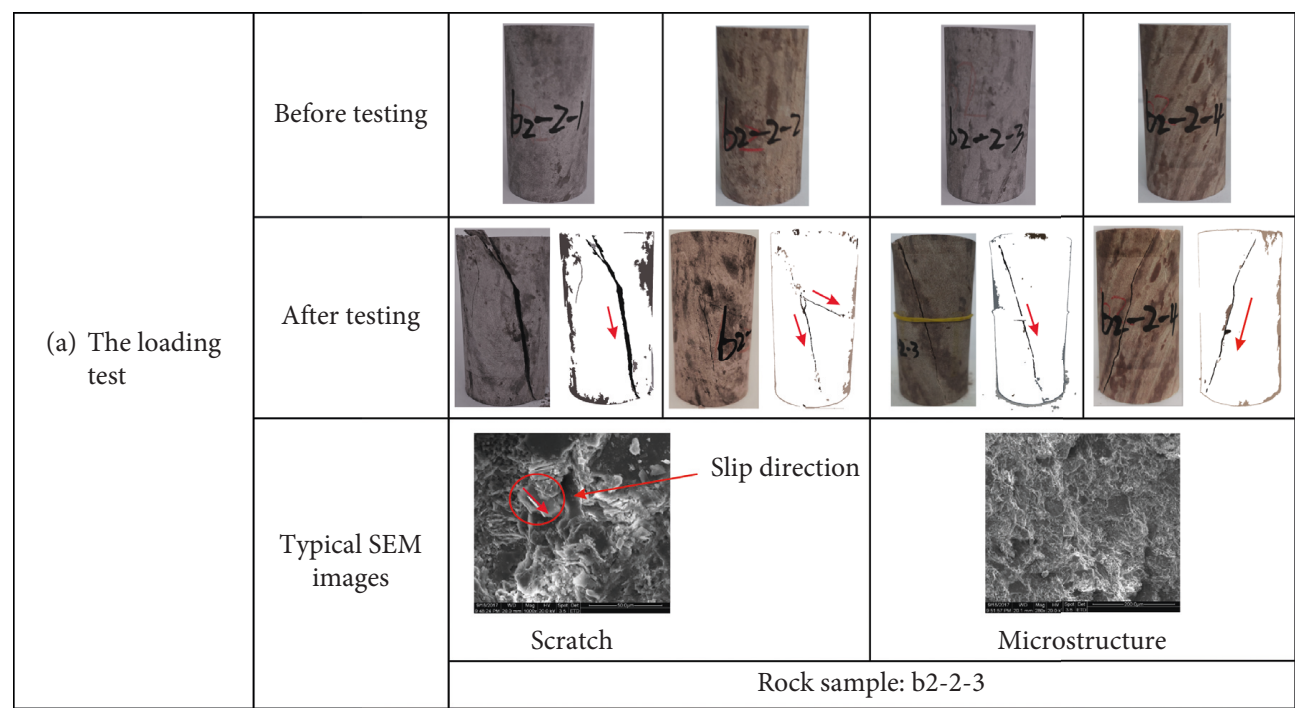

(a)

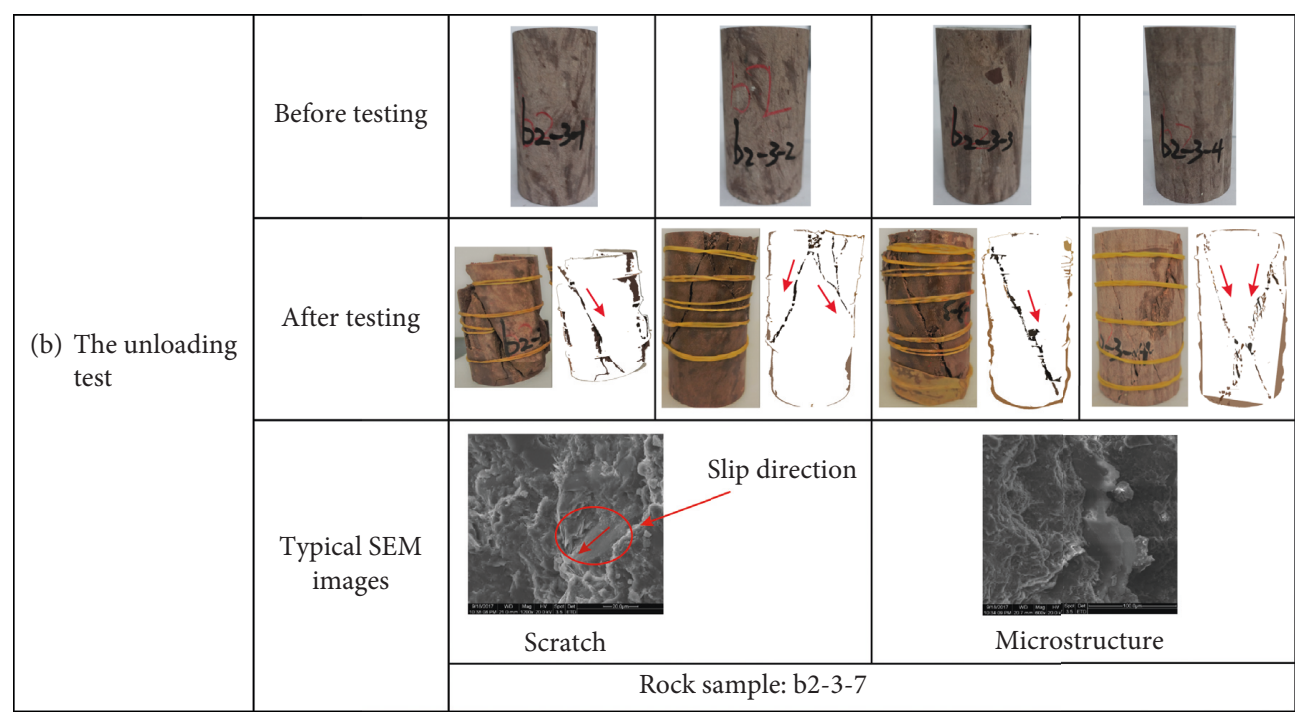

(b)

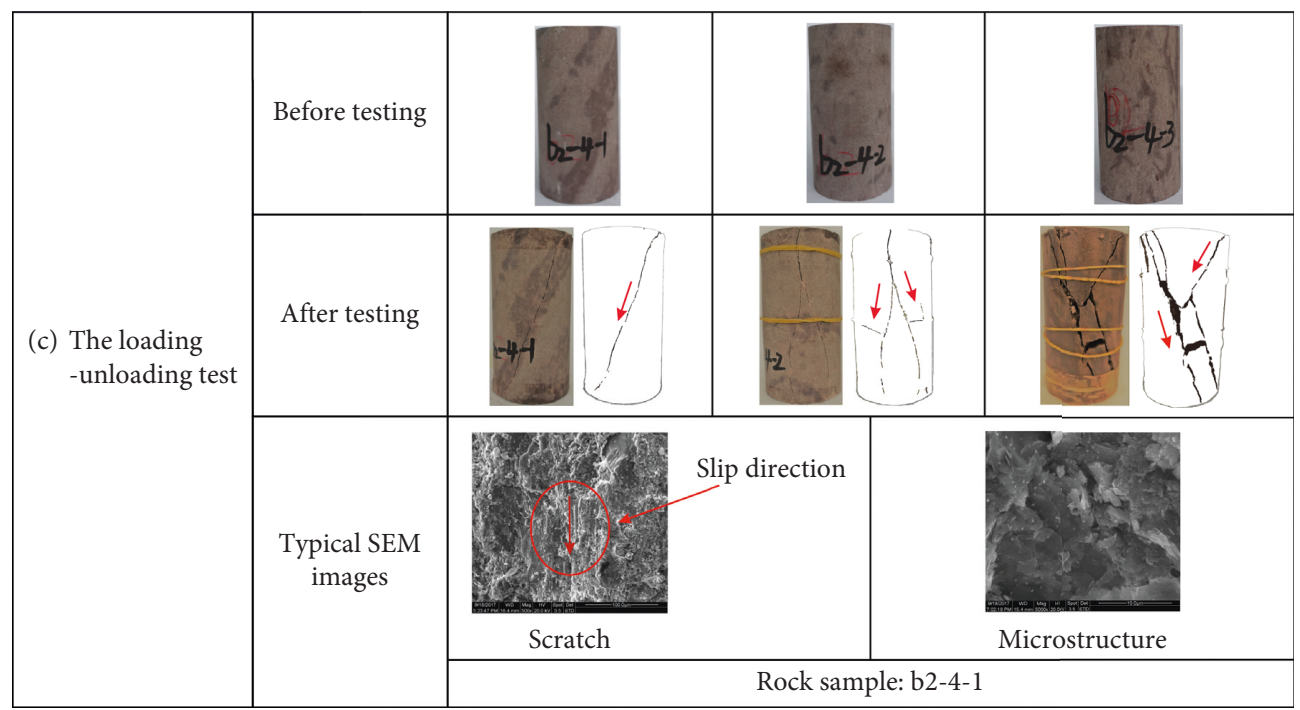

(c)

FIGURE 12: The failure modes and SEM images of rock specimens under different stress paths. 
elliptical rock powders exist in the partially uneven position and the particles have significant inhomogeneity. When the fracture surface is enlarged 5000 times, the shear scratches showed by the red circle and the slip direction showed by the red arrow in Figure 12(c) can also be obviously seen in the fracture surface, which indicates that the forces acting on the fracture surfaces are relatively concentrated and the contact forces between adjacent blocks are large when the blocks move.

By the SEM analysis, irregular quartz grains with a grain diameter of approximately $0.01-0.04 \mathrm{~mm}$ surrounded by clay minerals are revealed on the rock specimens under different confining pressures. Additionally, straight and smooth scratches are visible, as is a plurality of scratches parallel to each other, characterized by microcracks and clear boundaries. In the initial damage stage, the increase of unloading damage is due to the continuous increase of transgranular and intergranular cracks, which are the main source of the initial microcracks [38, 39]. Generally, once the stress exceeds the crack initiation stress, the boundaries of large grains are sleeker and more remarkable with the gradual development of microcracks and micropores. Simultaneously, small grains become smaller and smoother, and the structures of the rock specimens become looser, which eventually results in rock breaking along the fracture surface.

\section{Conclusions}

(1) For loading tests, the axial stress drops rapidly with a multilevel failure characteristic. The CDE is slightly lower than the ESE before the yield stage while the CDE increases more rapidly after the yield stage.

(2) For unloading tests, the failure of b2 rock without a multilevel failure characteristic is more sudden and severe. The evolution laws of the energy parameters are basically identical with the loading conditions, while the CDE before the PS is very little under unloading conditions.

(3) For the cyclic loading-unloading tests, the TAE, ESE, and CDE increase gradually with the increase of the cycle times. The increase trends of the TAE, ESE, and CDE in the first 5 cycles are consistent for different confining pressures. Moreover, the relationships between the CCDE and the axial strain are established by the exponential function.

(4) Under the loading conditions, the failure modes of the rock samples present shear fracture with a single surface while under the unloading conditions or the cyclic loading-unloading conditions, there are shear fracture, Y-shaped shear failure, and X-shaped shear failure and dense splitting fractures inside the rock samples under different confining pressures.

\section{Data Availability}

The data used to support the findings of this study are available from the corresponding author upon request.

\section{Conflicts of Interest}

The authors declare that they have no conflicts of interest.

\section{Acknowledgments}

This work was funded by the National Key R\&D Program of China (Grant no. 2017YFC1501305), China Postdoctoral Science Foundation (Grant no. 2018M642799), and the Key Laboratory of Well Stability and Fluid \& Rock Mechanics in Oil and Gas Reservoir of Shaanxi Province, Xi'an Shiyou University (Grant no. WSFRM20190101001).

\section{References}

[1] Y. Cai, Y. Jiang, I. Djamaluddin, T. Iura, and T. Esaki, “An analytical model considering interaction behavior of grouted rock bolts for convergence-confinement method in tunneling design," International Journal of Rock Mechanics and Mining Sciences, vol. 76, pp. 112-126, 2015.

[2] F. Meng, H. Zhou, Z. Wang et al., "Experimental study of factors affecting fault slip rockbursts in deeply buried hard rock tunnels," Bulletin of Engineering Geology and the Environment, vol. 76, no. 3, pp. 1167-1182, 2017.

[3] X.-X. Yang, H.-W. Jing, C.-A. Tang, and S.-Q. Yang, "Effect of parallel joint interaction on mechanical behavior of jointed rock mass models," International Journal of Rock Mechanics and Mining Sciences, vol. 92, pp. 40-53, 2017.

[4] Z. Hu, Y. R. Liu, S. Wu, W. Yi, and K. Wang, "Experimental study of deformation parameters degradation of sandstone in high geostress regions under unloading conditions," Rock and Soil Mechanics, vol. 35, no. S1, pp. 78-84, 2014.

[5] S. Wang, Y. Liu, J. Zhou, Q. Wu, S. Zhou, and Z. Zou, "Dynamic compressive characteristics of sandstone under confining pressure and radial gradient stress with the SHPB test," Advances in Civil Engineering, vol. 2018, Article ID 1387390, 8 pages, 2018.

[6] J.-W. Park, D. Park, D.-W. Ryu, B.-H. Choi, and E.-S. Park, "Analysis on heat transfer and heat loss characteristics of rock cavern thermal energy storage," Engineering Geology, vol. 181, pp. 142-148, 2014.

[7] P. L. P. Wasantha, P. G. Ranjith, and S. S. Shao, "Energy monitoring and analysis during deformation of beddedsandstone: use of acoustic emission," Ultrasonics, vol. 54, no. 1, pp. 217-226, 2014.

[8] R. Peng, Y. Ju, J. G. Wang, H. Xie, F. Gao, and L. Mao, "Energy dissipation and release during coal failure under conventional triaxial compression," Rock Mechanics and Rock Engineering, vol. 48, no. 2, pp. 509-526, 2015.

[9] T. Wen, Y. Liu, C. Yang, and X. Yi, "A rock damage constitutive model and damage energy dissipation rate analysis for characterising the crack closure effect," Geomechanics and Geoengineering, vol. 13, no. 1, pp. 54-63, 2018.

[10] A. V. Mikhalyuk and V. V. Zakharov, "Dissipation of dynamic-loading energy in quasi-elastic deformation processes in rocks," Journal of Applied Mechanics and Technical Physics, vol. 38, no. 2, pp. 312-318, 1997.

[11] E. D. Steffler, J. S. Epstein, and E. G. Conley, "Energy partitioning for a crack under remote shear and compression," International Journal of Fracture, vol. 120, no. 4, pp. 563-580, 2003. 
[12] V. Sujatha and J. M. C. Kishen, "Energy release rate due to friction at bimaterial interface in dams," Journal of Engineering Mechanics, vol. 129, no. 7, pp. 793-800, 2003.

[13] H. Munoz, A. Taheri, and E. K. Chanda, "Rock drilling performance evaluation by an energy dissipation based rock brittleness index," Rock Mechanics and Rock Engineering, vol. 49, no. 8, pp. 3343-3355, 2016.

[14] X. Wang, Y. Jiang, and B. Li, "Experimental and numerical study on crack propagation and deformation around underground opening in jointed rock masses," Geosciences Journal, vol. 21, no. 2, pp. 291-304, 2017.

[15] Y. Liu, J. Xu, and G. Zhou, "Relation between crack propagation and internal damage in sandstone during shear failure," Journal of Geophysics and Engineering, vol. 15, no. 5, pp. 2104-2109, 2018.

[16] A.-Z. Hua and M.-Q. You, "Rock failure due to energy release during unloading and application to underground rock burst control," Tunnelling and Underground Space Technology, vol. 16, no. 3, pp. 241-246, 2001.

[17] H. Xie, L. Li, Y. Ju, R. Peng, and Y. Yang, "Energy analysis for damage and catastrophic failure of rocks," Science China Technological Sciences, vol. 54, no. S1, pp. 199-209, 2011.

[18] L. Liu, Y. He, D. Liu, X. Wu, and R. Wang, “Temperaturedependent generalized planar fault energy and twinnability of $\mathrm{Mg}$ microalloyed with Er, Ho, Dy, Tb, and Gd: first-principles study," Advances in Materials Science and Engineering, vol. 2016, Article ID 4360321, 14 pages, 2016.

[19] B. Imre, S. Räbsamen, and S. M. Springman, "A coefficient of restitution of rock materials," Computers \& Geosciences, vol. 34, no. 4, pp. 339-350, 2008.

[20] D. Huang and Y. Li, "Conversion of strain energy in triaxial unloading tests on marble," International Journal of Rock Mechanics and Mining Sciences, vol. 66, pp. 160-168, 2014.

[21] X. Xu, Y. Dong, and C. Fan, "Laboratory investigation on energy dissipation and damage characteristics of frozen loess during deformation process," Cold Regions Science and Technology, vol. 109, pp. 1-8, 2015.

[22] M. Zhang, Q. Meng, and S. Liu, "Energy evolution characteristics and distribution laws of rock materials under triaxial cyclic loading and unloading compression," Advances in Materials Science and Engineering, vol. 2017, Article ID 5471571, 16 pages, 2017.

[23] X. S. Liu, J. G. Ning, Y. L. Tan, and Q. H. Gu, "Damage constitutive model based on energy dissipation for intact rock subjected to cyclic loading," International Journal of Rock Mechanics and Mining Sciences, vol. 85, pp. 27-32, 2016.

[24] B. Sun, Z. Zhu, C. Shi, and Z. Luo, "Dynamic mechanical behavior and fatigue damage evolution of sandstone under cyclic loading," International Journal of Rock Mechanics and Mining Sciences, vol. 94, pp. 82-89, 2017.

[25] Q. Wu, Y. J. Xu, H. M. Tang et al., "Peak shear strength prediction for discontinuities between two different rock types using a neural network approach," Bulletin of Engineering Geology and the Environment, pp. 1-15, 2018.

[26] Y. P. Yin and R. L. Hu, "Engineering geology characteristics of purplish-red mudstone of middle tertiary formation at the three gorges reservoir," Journal of Engineering Geology, vol. 12, no. 2, pp. 124-135, 2004.

[27] H. F. Lu, C. X. Chen, C. H. Yuan, H. D. Yu, and Q. Shen, "Analysis of failure mechanism of badong red bed soft rock gently inclined bedding slope," Chinese Journal of Rock Mechanics and Engineering, vol. 29, no. 2, pp. 3569-3577, 2010.
[28] P. Shen, H. Tang, L. Huang, and D. Wang, "Experimental study of slaking properties of red-bed mudstones from the three gorges reservoir area," Marine Georesources \& Geotechnology, pp. 1-11, 2018.

[29] M. Singh, A. Raj, and B. Singh, "Modified Mohr-Coulomb criterion for non-linear triaxial and polyaxial strength of intact rocks," International Journal of Rock Mechanics and Mining Sciences, vol. 48, no. 4, pp. 546-555, 2011.

[30] M. H. Mehranpour, P. H. S. W. Kulatilake, M. Xingen, and M. C. He, "Development of new three-dimensional rock mass strength criteria," Rock Mechanics and Rock Engineering, vol. 51, no. 11, pp. 3537-3561, 2018.

[31] X. Wang, Z. Wen, Y. Jiang, and H. Huang, "Experimental study on mechanical and acoustic emission characteristics of rock-like material under non-uniformly distributed loads," Rock Mechanics and Rock Engineering, vol. 51, no. 3, pp. 729-745, 2018.

[32] X. Wu, Y. Jiang, and Z. Guan, "A modified strain-softening model with multi-post-peak behaviours and its application in circular tunnel," Engineering Geology, vol. 240, pp. 21-33, 2018.

[33] M. Ismael and H. Konietzky, "Constitutive model for inherent anisotropic rocks: ubiquitous joint model based on the hoekbrown failure criterion," Computers and Geotechnics, vol. 105, pp. 99-109, 2019.

[34] L. M. Zhang, S. Gao, Z. Q. Wang, and Y. Cong, "Analysis of marble failure energy evolution under loading and unloading conditions," Chinese Journal of Rock Mechanics and Engineering, vol. 32, no. 8, pp. 1572-1578, 2013.

[35] T. Wen, H. M. Tang, J. W. Ma, and Y. R. Liu, "Energy analysis of the deformation and failure process of sandstone and damage constitutive model," KSCE Journal of Civil Engineering, vol. 23, no. 2, pp. 523-524, 2018.

[36] J. Shen, S. D. Priest, and M. Karakus, "Determination of mohr-coulomb shear strength parameters from generalized hoek-Brown criterion for slope stability analysis," Rock Mechanics and Rock Engineering, vol. 45, no. 1, pp. 123-129, 2012.

[37] G. Wang, Y. Zhang, Y. Jiang et al., "Shear behaviour and acoustic emission characteristics of bolted rock joints with different roughnesses," Rock Mechanics and Rock Engineering, vol. 51, no. 6, pp. 1885-1906, 2018.

[38] M. S. Diederichs, P. K. Kaiser, and E. Eberhardt, "Damage initiation and propagation in hard rock during tunnelling and the influence of near-face stress rotation," International Journal of Rock Mechanics and Mining Sciences, vol. 41, no. 5, pp. 785-812, 2004.

[39] S.-c. Hu, Y.-l. Tan, H. Zhou et al., "Impact of bedding planes on mechanical properties of sandstone," Rock Mechanics and Rock Engineering, vol. 50, no. 8, pp. 2243-2251, 2017. 


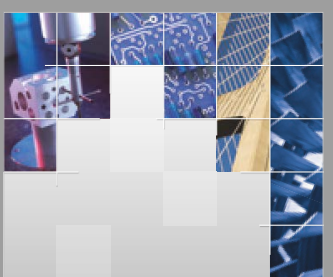

\section{Enfincering}
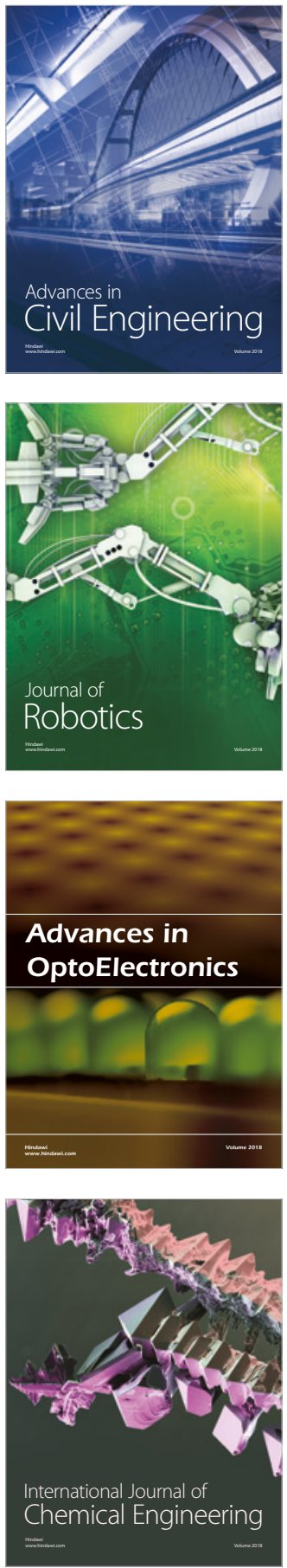

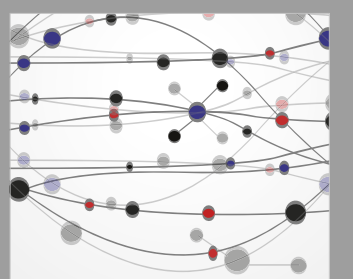

\section{Rotating \\ Machinery}

The Scientific World Journal

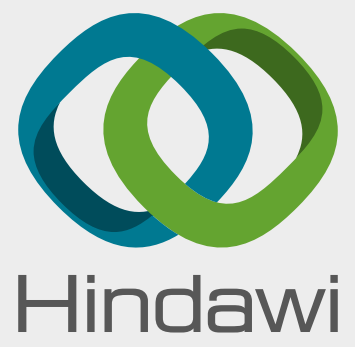

Submit your manuscripts at

www.hindawi.com
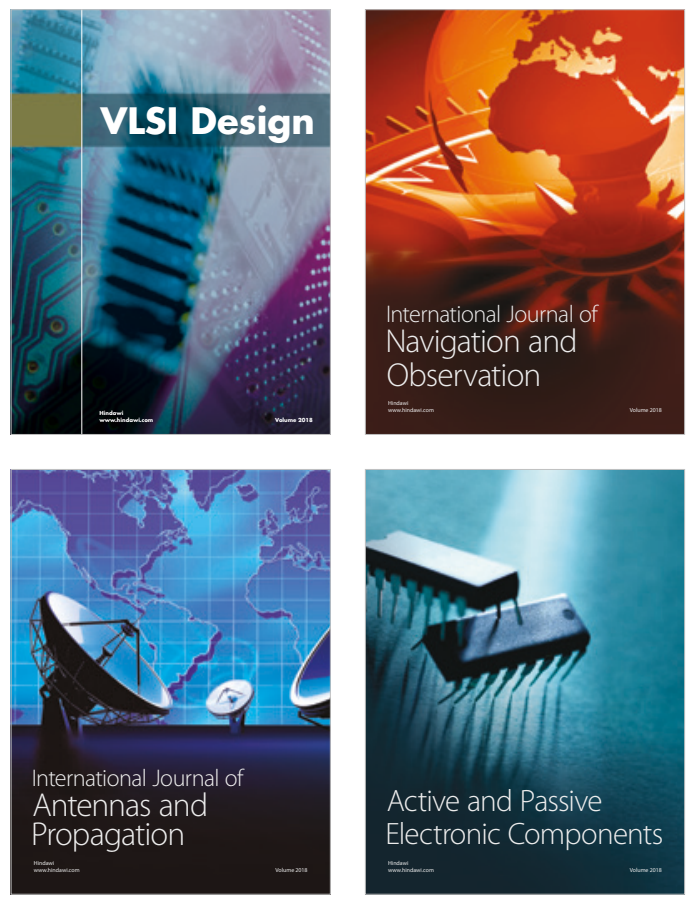
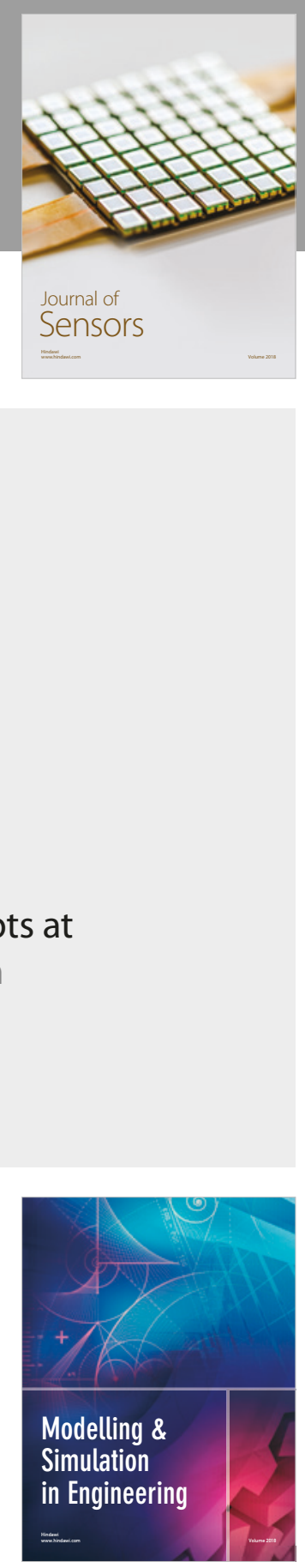

\section{Advances \\ Multimedia}
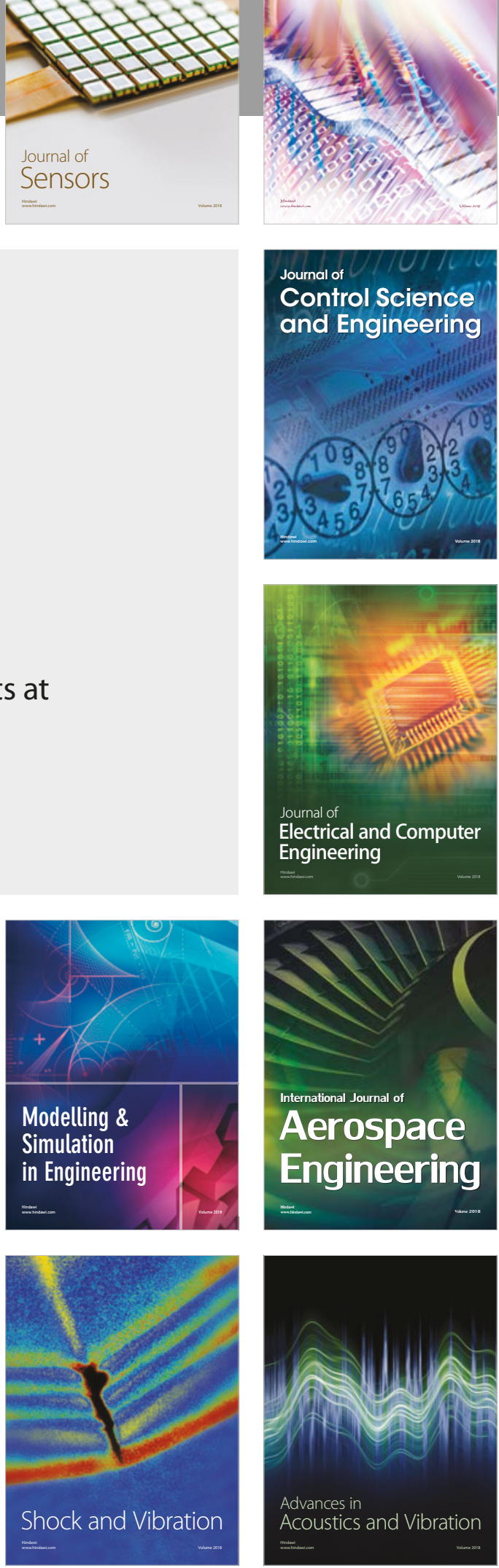